\author{
UNIVERSTTY OF CALIFORNIA \\ Radiation Laboratory \\ Contract No. W-7405- eng - 48
}

THE PATH OF CARBON IN PHOTOSYNTHESIS .XXI. THE CYCLIC REGENERATION OF CARBON DIOXIDE ACCEPTOR

J.A. Bassham, A. Benson, Lorel D. Kay, Anne $Z$. Harris, A. T. Wilson and $M_{0}$ Calvin

October, 1953

Berkeley, California 
THE PATH OF CARBON IN PHOTOSYNTHESIS: XXI. THE CYCLIC REGENERATION OF CARBON DIOXIDE ACCEPTOR

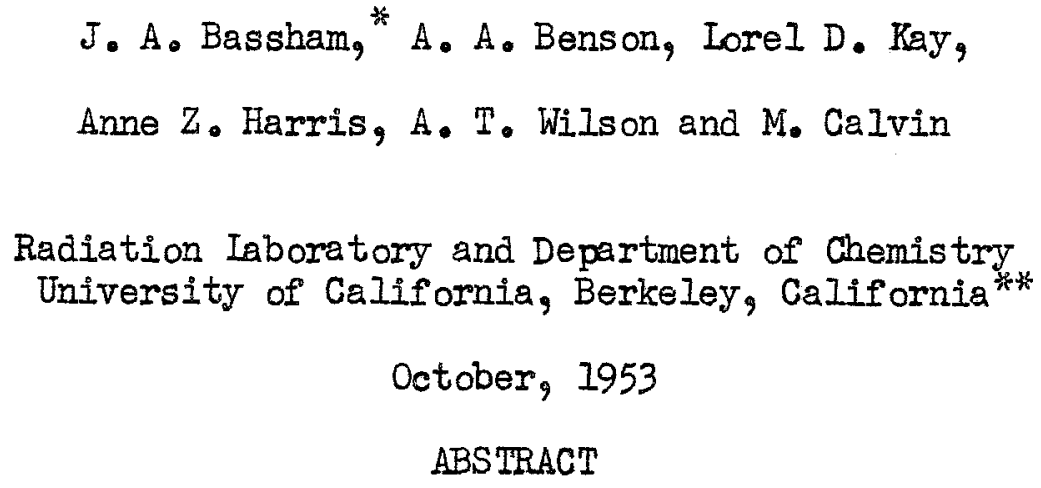

Photosynthesizing plants have been exposed to $\mathrm{C}^{14} \mathrm{O}_{2}$ for short periods of time (0.4 to 15 sec.) and the prodacts of carbon dioxide reduction analyzed by paper chromatography and radioautography.

Methods have been developed for the degradation of ribulose and sedoheptulose. These sugars, obtained as their phosphate esters from the above $\mathrm{C}^{1 / 4} \mathrm{O}_{2}$ exposures and from other experiments, have been degraded and their distribution of radiocarbon determined.

The distribution of radiocarbon in these sugars, and other data, indicate that sedoheptulose phosphate and ribulose diphosphates are formed during photosynthesis from triose and hexose phosphates, the latter being synthesized, in turn, by the reduction of 3-phosphoglyceric acid.

This paper was presented before the Division of Biological Chemistry, American Chemical Society at the 124th National Meeting, Chicago, Illinois, September 1953.

* The work described in this paper was sponsored by the U. S. Atomic Energy Cormission. 
Further evidence has been found for the previously proposed carboxylation of ribulose diphosphate to phosphoglyceric acid. Free energy calculations indicate this step would proceed spontaneousiy if enzymatically catalyzed.

The efficiency of this cycle for reduction of $\mathrm{CO}_{2}$ to hexose would be 0.9 if the reduction of each molecule of $P G A$ requires the concurrent conversion of one molecule of ATP and one of DPN (red) to ADP, inorganic phosphate, and DPN (ox.). This mechanism, together with an assumed mechanism for the photolysis of water, would lead to an efficiency of about 0.5 for the overall photosynthetic reaction and a requirement of about six quanta of light per molecule of $\mathrm{CO}_{2}$ reduced to carbohydrate. 
THE PATH OF CARBON IN PHOTOSYNTHESIS. XXI。 THE CYCLIC REGENERATION OF CARBON DIOXIDE ACCEPTOR

J. A. Bassham, A. A. Benson, Lorel D. Kay, Anne Z. Harris, A. T. Wils on and M. Calvin

Radiation Iaboratory and Department of Chemistry University of Califormia, Berkeley, California

Previously reported tracer studies of the path of carbon in photosynthesis ${ }^{2}$ led to the conclusion that carbon is incorporated by a carboxylation reaction leading to phosphoglyceric acid $(\mathrm{PGA})^{3}$ which is then reduced and condensed to fructose and glucose phosphates by a series of reactions similar to a reversal of glycolysis. These conclusions were supported by the observations that when carbon- $1_{4}$ is administered to the photosynthesizing plant as $\mathrm{C}^{\mathrm{H}_{4}} \mathrm{O}_{2}$, the first redioactive compound isolated is carboxyl-labeled PGA, followed shortly by difydroxyacetone phosphate (DHAP), fructose monophosphates (FMP) and glucose monophosphate (GMP), both hoxoses being 3,4-labeled. After longer exposures of the plant to $\mathrm{C}^{1 / 4} \mathrm{O}_{2}$, radiocarbon appears in other carbon atoms of $\mathrm{PGA}$ and hexose and the distribution of activity is in agreement with the above conclusions.

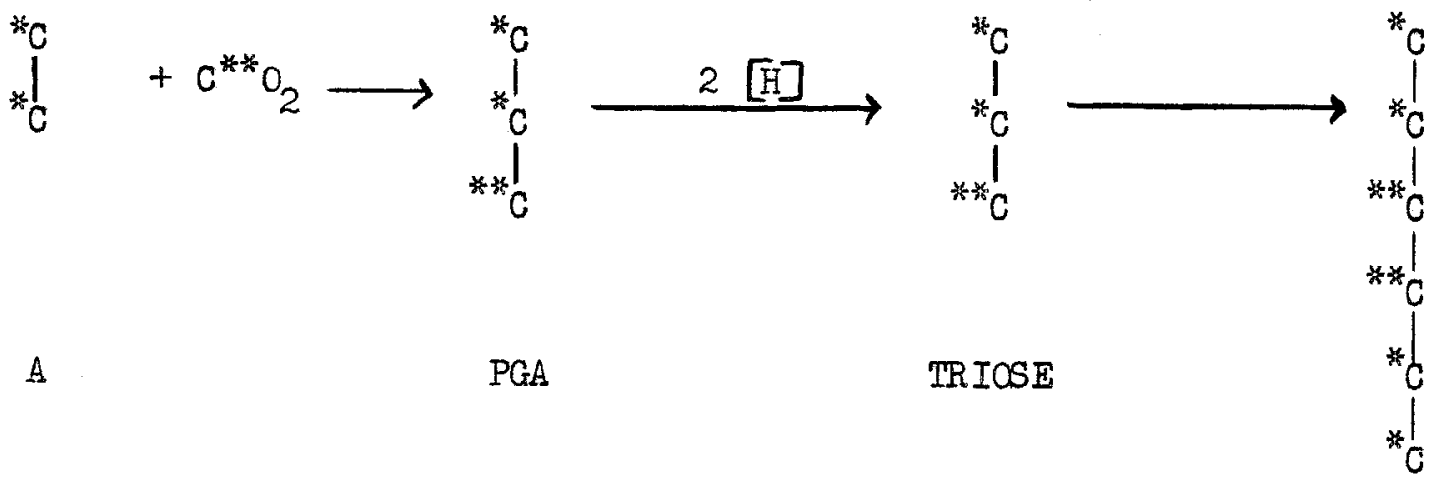


Observations on the rate and alstribution of labeling of malic acid $4,5,6$ showed it to be the eventual product of a second carboxylation reaction which is accelerated during photosynthesis, and it was proposed that this second carboxylaw tion played a part in the reduction of carbon in photosynthesis, leading even tually to the fommation of the twomcarbon $\mathrm{CO}_{2}$ acceptor ( $\mathrm{A}_{9}$ above). Malic acid, itself, was apparently precluded as an actual intermediate by inhibition studies, ${ }^{7}$ but was thought to be an indicator of an unstable intermediate which was actually the first product of the second carboxylation. The discovery ${ }^{8}$ of rapidly labeled sedoheptulose monophosphate (SMP) and ribulose diphosphate (RDP) led to their inclusion in the proposed carbon reduction cycle leading to the twowcarbon $\mathrm{CO}_{2}$ acceptor.

The reciprocal changes in reservoir sizes of $\mathrm{RDP}$ and $\mathrm{PGA}$ observed when algae were subjected to light and dark periods ${ }^{9}$ indicated a close relationship, perhaps identity, between the RDP and the two-carbon $\mathrm{CO}_{2}$ acceptor.

In order to test these conclusions, it was necessary to design experiments involving very short exposures of the plant to $\mathrm{C}^{14} \mathrm{O}_{2}$. In some of these experiments, the $\mathrm{C}^{14}$ was administered during "steady state" photosynthesis, the environmental conditions (Iight, carbon dioxide pressure, etco) being kept as nearly constant as possible for the hour preceeding and the time during the experiment. Degradation methods have been developed for sedoheptulose and ribulose and complete distributions of radioactivity within these sugars obtained. 
The results of these experiments seem to obviate the possibility that the second carboxylation reaction (leading to malic acid) is a step in carbon reduction during photosynthesis. Since no new evidence has been found for the second "photosynthetic" carboxylation, it would appear that a carbon reduction cycle involving only one carboxylation (leading to $P G A$ ) is more likely than the previously proposed two-carboxylation cycle.

\section{Fxperimenta] Procedure}

Short "Steady State" Experiments, - Algae (Scenedesmus obliquus) were grown under controlled conditions, ${ }^{5}$ centrifuged from the growth medium, and resuspended in a $1 \%$ by volume suspension in distilled water. This suspension was placed in a rectangular, water-jacketed illumination chamber $6 \mathrm{~mm}$ 。 thick, through which was passed a continuous stream of $4 \% \mathrm{CO}_{2}$-in-air. (Figure 1 ). From the bottom of the changer, a transparent tube led to a small transparent pump constructed of appropriately placed glass valves and two $5 \mathrm{cc}$. glass syringes mounted on a lever arm in such a position that the syringe plungers moved in and out reciprocally about $5 \mathrm{~mm}$. when the lever arm was moved back and forth by a motor-driven eccentric. The output of the pump was divided, the major portion being returned to the illumination chamber and a smaller portion ( $20 \mathrm{ml} / \mathrm{minute}$ ) forced to flow through a length of transparent "Transflex" tubing of about Imm. diameter and thence into a beaker containing boiling methanol. This solvent was 
found to have an apparent killing time of less than 0.2 secoas determined by the cessation of carbon firation during photosyntbesis. The linear flow rate of alo gal suspension in the tube was about $57 \mathrm{~cm} /$ second. A solution of $\mathrm{C}^{\mathrm{I}_{4}} \mathrm{O}_{2}$ in water $\left(0.0716 \mathrm{Mg} 110 \mu_{\mathrm{c}} / \mathrm{ml}_{0}\right)$ in a $30 \mathrm{cc}$ syringe was injected through a fine hypodermic needle into the Transflex tubing at a point a selected distance from the end of the tubing. From the known flow rate of algal suspension in the Transflex tubing and distance of flow from the point of injection of $\mathrm{C}^{14} \mathrm{O}_{2}$ to the killing soluo tion, the time of exposure of the algae to $\mathrm{C}^{14}$ was calculated. The flow of the $\mathrm{C}^{14} \mathrm{O}_{2}$ containing solution was controlled by ariving the syringe plunger with a constant speed motor, and the flow rate was $0.5 \mathrm{ml} / \mathrm{minute}_{0}$ The resultant dilution of the algal suspension was $2.5 \%$ and the increment in total $\mathrm{CO}_{2}$ concentration less than $15 \%$.

Since the flow of algal suspension in the tubing was not turbulent, some difference in rates of flow at the center and at the edge of the tuibing was un avoidable. The extent of this difference was approximately determined by in jecting a concentrated dye solution for about 0.5 sec. through the hypodermic needle while the flow rate in the tubing was $20 \mathrm{mI} /$ minute and observing the spreading of color during its travel through the tubing. For the longest length of tubing used, the dye was seen to reach the end of the tubing between $I_{4}$ and 17 seconds, and at a shorter time between 9 and 11 seconds $s_{9}$ so that the spread of flow in time appeared to be about $20 \%$ of the flow time. The times given are average times of exposure of the algae to $\mathrm{c}^{\mathrm{I}_{4}}$. Use of the dye also permitited observation of the mixing of $\mathrm{C}^{\mathrm{H}_{4}} \mathrm{O}_{2}$ solution with algal suspension and mixing time appeared to be about 0.2 sec。

The entire apparatus was illuminated from each side by a nine-tube bark of 40-watt fluorescent lights (white) giving a uniform intensity of about 2000 
footcandles from each side. During an experiment the algal suspension was illuminated for an hour or more with $4 \% \mathrm{CO}_{2}$ before the start of the flow $\mathrm{c}^{14}$ exposures. Exposures to $\mathrm{c}^{14} \mathrm{O}_{2}$ ranging from 1.0 to $16 \mathrm{sec}$. were then carried out and the products of $\mathrm{C}^{\mathrm{H}_{\mathrm{H}}} \mathrm{O}_{2}$ reduction analyzed in the usual way ${ }^{10}$ by paper chromatography and radioautography.

Short Soy Bean Experiments. - A single excised trifoliate leaf from a soy bean plant (var. Hawkeye) was placed in a circular flat illumination chamber with a detachable face. The chamber was equipped with two tubes, the lower one leading through a stopcock to an aspirator and the upper one through a twom way stopcock to a loop containing $\mathrm{C}^{1 / 4} \mathrm{O}_{2}$. A loosely tied thread led from the leaf stem under the detachable face gasket, thence through a boiling ethanol bath and a glass tube to a weight. The illumination chamber was partialiy evacuated, both stopcocks were closed, and clamps removed from the chamber, the detachable face remaining in position through atmospheric pressure. With the opening of the upper stopoock, the $\mathrm{C}^{1 / 4} \mathrm{O}_{2}$ was swept into the chamber by atmospheric pressure, the detachable face fell off and the leaf was pulled into boiling ethanol. An estimated exposure time of 0.4 sec. was obtained. The radioactive products were extracted and analyzed in the usual way. In other experiments, longer exposure times were obtained by holding the detachable face in position. 
Degradation of Sugars, - The reactions used for the degradation of the radionctive ribulose and sedoheptulose are as follows:

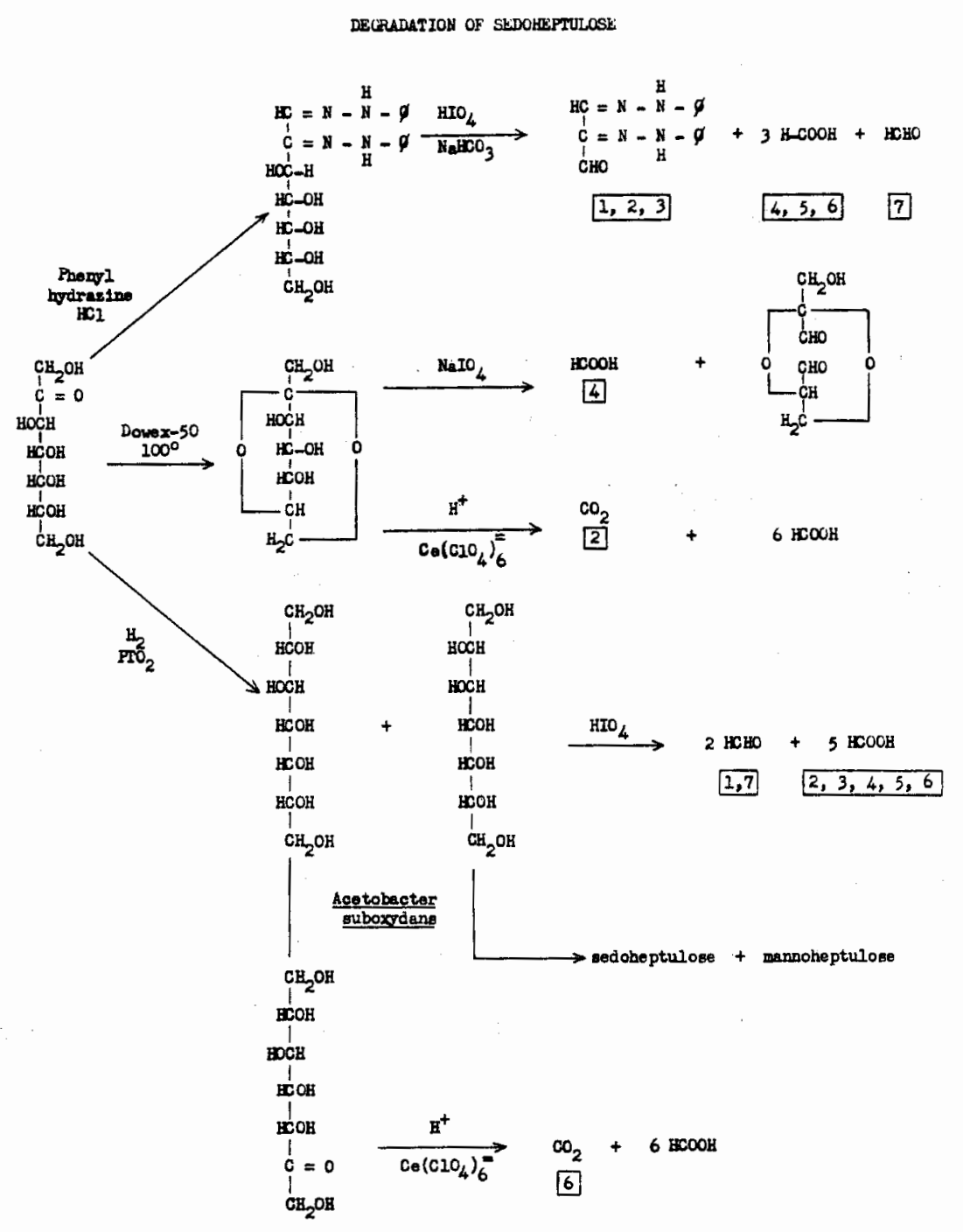

MU-6100 A 


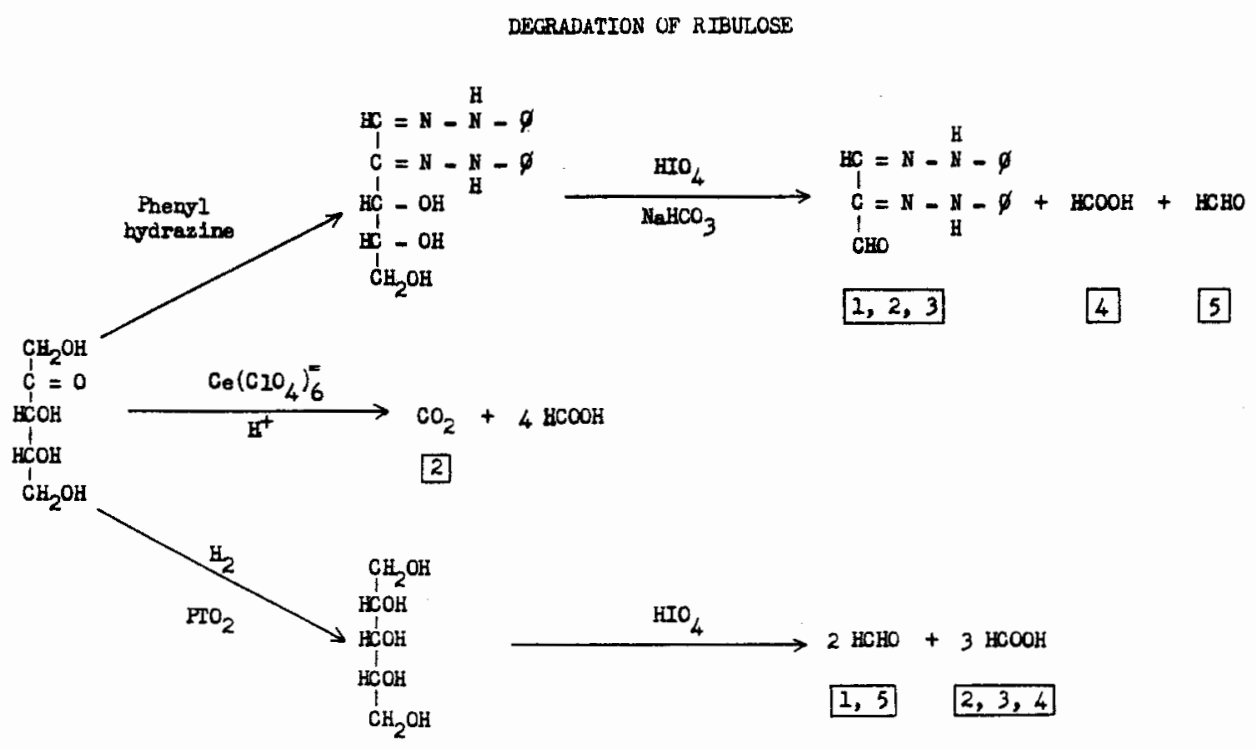


All radioactive material was purified on twomimensional paper chromatograms. 10 Radioactive sedoheptulose was converted to the anhydride by heating at $100^{\circ}$ with acidotreated Dowex-50 for one hour, followed by chromatography to separate the resulting equilibrium mixture.

Formation of the Osazones. - The hexose and heptose osazones were made In the usual manner with phenylhydrazine hydrochloride, sodium acetate and acetic acid. Usually about $25 \mathrm{mg}$ o of sugar carrier was used for the reaction. Sedoheptulose osazone comcrystallized with glucosazone sufficiently well for fructose to be used as carrier with sedoheptulose activity.

The radioactive arabinosazone was made by the method of Haskins, Hann and Hudson ${ }^{11}$ with $10 \mathrm{mg}$. of arabinose carrier. The osazone was recrystallized once and diluted, as desired for each degradation, with pure crystaliine, nonradioactive arabinosazone from a similar large-scale preparation.

Oxidation of Osazones, - The recrystallized osazones were treated with periodate in bicarbonate buffer as described by Topper and Hastings. 12 The reaction mixture was fractionated to obtain all the products by centrifuging and thoroughly washing the mesoxaldehyde ostzone; distilling the supernate plus washings to dryness in vacuo and treating the distillate with dimedon to obtain the formaldehyde derivative; and acidifying and vacuum-distilling the residue to obtain the formic acid, which was counted as barium formate. AII products were recrystallized before counting.

Cerate Oxidation of Ketoses. - The oxidation of the carbony carbon of a ketose to $\mathrm{CO}_{2}$ by cerate ion was performed according to the method described by Smith. ${ }^{13}$ To a solution of an aliquot portion of radioactivity plus weighed carrier (sedoheptulosan or fructose) was added a sifght excess of $0.5 \mathrm{M}$ cerate ion $^{14}$ in $6 \mathbb{N}$ perchloric acid, the final concentration of acid being $4 \mathbb{N}$. The resultant $\mathrm{CO}_{2}$ was swept with nitrogen into $\mathrm{CO}_{2}$ free sodium hydroxide. The 
reaction was allowed to proceed for one hour at room temperature and then the $\mathrm{CO}_{2}$ was precipitated and counted as barium carbonate. In all cases the theoretical amount of carbon dioxide was evolved.

Formation and Oxidation of Sugar Alcohols. - The radioactive sugars were hydrogenated with platinum oxide as described previous $1 y^{8}$ and chromatographed on paper for purification. Carrier ribitol or volemitol was added to an aliquot of radioactive alcohol and a slight excess of para periodic acid was added. The reaction was allowed to stand at room temperature for 6-7 hours. Then the formic acid and formaldehyde were distilled off in vacuo. After the formic acid was titrated with barium hydroxide, the formaldehyde was redistilled and precipitated as formyldimedon. Both the residue of barium formate and the formy lo dimedon were recrystallized before plating and counting.

Bacterial Oxidation of Hepitols from the Reduction of Sedoheptulose, $\infty$ The radioactive reduction products of sedoheptulose gave only one spot on chromatography. After elution these were oxidized by Acetobacter suboxydans in a small-scale modification of the usual method. 15 Two mg. of volemitol and about $100 \mu_{I}$. of solution of radiactive heptitols were placed in a $7 \mathrm{~mm}$. diameter vial. An amount of yeast extract sufficient to make a $0.5 \%$ solution was added. The vial was sterilized, then inoculated from a 24-hour culture of Acetobacter and left for a week at room temperature in a humid atmosphere.

When the bacteria were centrifuged from the incubation mixture and the super natant solution was chromatographed, three radicactive spots were obtained. The two major spots were mannoheptulose and sedoheptulose, the oxidation products of volemitol. The third had $R_{f}$ values very similar to those of fructose and cochromatographed with authentic guloheptulose ${ }^{16}\left(R_{f}\right.$ in phenol $=.47$; $R_{f}$ in butanol-propionic acid-water $=.24$ ). After treatment with Dowex-50 in the acid form at $100^{\circ} \mathrm{C}$ for one hour, this third compound gave a new compound which 
cochromatographed with guloheptulosan $\left(R_{f o}\right.$ in phenol $=.62: R_{f}$ in butanolpropionic acid-water $=030)$. It thus appeared that the radioactive heptitiols are volemitol and $\beta$-sedoheptitol which cochromatograph in the solvents used. Both mannoheptulose and guloheptulose have carbon chains inverted from the original sedoheptulose. In the small-mscale fermentations, however, the oxidation appeared to be incomplete. The original alcohol did not separate chromatographically from mannoheptulose. Therefore, the easily purified guloheptulose was used for subsequent degradations with cerate ion, despite its much poorer yield.

Oxidation of Sedoheptuiose - The radioactive sample and carrier were treated with sodium periodate as described by Pratt, Richtmeyer and Hudson ${ }^{27}$ and allowed to stand at room temperature for $3=4$ days to give time for most of the formate to be released from the intermediate ester. Then the mixture was acidified with iodic acid and the formic acid was distilled in vacuo. This was then counted as barium formate.

\section{ResuIts}

In Figure 2 , the radiocarbon fixed in a "steady state" photosynthesis with Scenedesmus is shown as a function of time of exposure of the plant to $\mathrm{C}^{14} \mathrm{O}_{2}$ 。 The rate of incorporation of $\mathrm{C}^{1 / 4} \mathrm{O}_{2}$ appears to be reasonably constant over the period of the experiment. The distribution of racioactivity among various labeled compounds is shown in Figure 3. The curve for the sugar diphosphates, 
principally ribulose diphosphate, is not shown but lies between the gincose monom phosphate curves although individual points are more erratics probably due to the relative instability of the ribulose diphosphate. 8 The appearance of compounds other than PGA with a finite rate of labeling at the shortest times is demonstrated In Figure 4 in which the pereentage distributions of PGA and of the total sugar phosphates are shown. The extrapolations of the PGA and sugar phosphates to zero time would give about $75 \%$ and $17 \%$, respectively. The remaining eight per cent not show is distirbuted among malis acid (3\%), free glyceric acid (2\%) and phosphoenolpyruvic acid $(3 \%) 0_{0}^{9}$ The percentage distribution among the sugar phosphates is shown in Figure 5 where it is seen that no single labeled sugar phosphate predominates at the shortest times.

These data alone do not permit assignment of an order of precedence of the rarious labeled compounds in the path of carbon reduction. In order to make such an assignment it would be necessary to measure the relative rates of increase in specific acitivity of the various compounds. If the slopes of the curves show in Figure 3 are measured between 2 and 10 sec.g rates of increase in total radio activity are obtained. If these rates are divided by the cellular concentration of the compounds involved, rates of specific activity increase are obtained. This has been done using measurements of concentrations made by two independent 9,18 methods which agreed fairly well in relative order (i.e.g PGA concentration: GMF concen tration $=4: 1)$. The resulting ralues ranged from 0.3 for GMP to 1.0 for PGA, with FMP, DHAP, RDP and SMP faliing between these values when the rates for these compounds were divided by $2, I_{g} 2_{q} I_{g} I_{g}$ and 3, respectively, to allow for the number of carbon atoms which degradation data reported below show to be labeled signifize cantly at these short times. This calculation is quite approximate, the con centration of compounds involved being measured in experiments with algae photow 
synthesizing under somewhat different conditions (i.e.\% $1 \% \mathrm{CO}_{2}$ instead of $4 \%$ ). However, such a calculation does show more clearly the rapidity with which radio carbon is distributed among the principaliy labeled carbonktoms and the diffim culty in assigning an order of precedence of labeled compounds on the basis of labeling rates alone。

The fact that compounds besides PGA have finite initial labeling slopes (which results in their percentage activity not extrapolating to zero at zero time) might be explained in several ways. One possibility is that during the killing time some of the enzymatic reactions fin this case reduction of PGA and rearrangement of the sugars) may not be stopped as suddenly as others (the caro boxylation to give PGA) or may even be accelerated by the rising temperature prior to enzyme denaturation.

Arother explanation is that some of the labeled molecules may be passed from enzyme to enzyme without completely equilibrating with the active reservoirs which are actually being measured. This sort of enzymatic transfer cf radiocarbon could invalidate precedence assignments based on rates of increase in specific activities since the reservoirs would no longer be completely in the line of carbon transfer. That the equilibration between reservolrs and enzyne-substrate complexes is rapid compared to the carbon reduction cyole as a whole is indicated by the fact that all the reservoirs become appreciably labeled before there is an appreciable labeI in the $\alpha^{-1}$ and $\beta$ carbons of $P G A$, the $I_{0}, 5$ and 6 carbons of the hexoses, etc. In any event, it would appear to be safer to establist the reaction sequences from qualitatite differenoes in labeling within molecules (degradation data) and changes in reservoir sizes due to controlled changes in one environmental variable rather than from quantitative interpretations of labeling rate data. 
Table I shows the results of degradations on sugars obtained from the soy bean series. The first column shows the variation in labeling of carbon number four of sedoheptulose obtained from soy bean leaves exposed to $\mathrm{C}^{\mathrm{I}_{4}} \mathrm{O}_{2}$ for very short periods. These soy bean leaf experiments are, of course, not intended to represent "steady state" photosynthesis since the carbon dioxide is depleted just prior to the administration of $\mathrm{C}^{1 / 4} \mathrm{O}_{2}$. Included in the table is a complete degradation of a sedoheptulose sample from Sedum spectabile grown in radio active carbon dioxide for two days (kindiy supplied by N. E. Tolbert, Oak Ridge National Iaboratory). Assuming this sample is uniformly labeled, its degradation indicates the probable limits of accuracy of the other degradations - about $\pm 10 \%$ of the obtained value, mainly due to plating and counting errors resulting from the low amount of radioactivity available for degradation. The five degradations on sedoheptulose make it possible to obtain separate values for all the carbon atoms. Although the carbon-fourteen labels of carbon atoms $I$ and 6 were not determined in the case of the Scenedesmus experiments, they were assumed small and approximately equal to carbon-fourteen labels found in carbons 2 and 7, by analogy with the soy bean leaf experiments where the labels of all carbon atoms of the sedoheptulose were determined. The label in each carbon atom of the ribulose can be obtained individually from the three degradations performed. The distributions in Table II should be interpreted as a clear qualitative picture of the position of the radioactivity within the molecule rather than as a quantitative picture. Fewer points were taken in this "steady state" flow experiment than in the one described earlier in order to obtain more labeled sugar per point for degradation purposes. 
Tabie I

RADIOACTIVTTY DISTRIBUTION IN STGABS

SEDOHEFTUIOSE AND HEXOSE FROM SOY BEAN IEAVES

\begin{tabular}{|c|c|c|c|c|c|c|c|c|c|}
\hline \multirow{2}{*}{$\begin{array}{l}\text { Time, } \\
\text { seconds }\end{array}$} & \multicolumn{7}{|c|}{ Sedoheptulose } & \multicolumn{2}{|c|}{ Hexose } \\
\hline & $0=0$ & $C=1,2,3$ & $C-4,5,6$ & $\mathrm{C}-\mathrm{-}$ ? & $\mathrm{C}-2$ & $0-1,7$ & $0-6$ & $\mathrm{C}-\mathrm{I}, 2,2,3$ & $C-4,5,6$ \\
\hline 0.4 & 8 & 33 & 57 & 0 & & - & & 47 & 52 \\
\hline 0.8 & 18 & 43 & 60 & 2 & & & & 48 & $5 I$ \\
\hline 1.5 & 24 & & & & & & & & \\
\hline 3.5 & 26 & & & & & 3 & & & \\
\hline$=5.0$ & 29 & 36 & 64 & 2 & 4 & 4 & 4 & & \\
\hline 8.0 & 24 & & & & & & & & \\
\hline 10.0 & 28 & & & & & & & & \\
\hline 20.0 & 21 & 44 & $+\infty$ & 5 & 7 & & & & \\
\hline 300 & $L_{4}$ & & & & 12.5 & & & & \\
\hline Sedum. & 12 & 37 & 35 & 12 & 12.5 & 28 & 25 & & \\
\hline
\end{tabular}


Table II

RADIOACTIVITY DISTR IBUTION IN GOMPOUNDS

FROM F IOW EXPER IMENTS

(AIGAI)

\begin{tabular}{|ccc|c|}
\hline \multicolumn{2}{|c|}{5.4 Seconds } & \multicolumn{2}{c|}{8.5 Seconds } \\
\hline $\begin{array}{c}\text { Glyceric } \\
\text { Acid }\end{array}$ & Fructose Sedoheptulose & Ribulose & Sedoheptulose Ribulose \\
\hline & 2 & \\
\hline 3 & 2 & 11 & 11 \\
\hline 3 & 28 & 10 & 11 \\
\hline 43 & 24 & 69 & 64 \\
\hline 42 & 27 & 5 & 5 \\
\hline 3 & 2 & 3 & 5 \\
\hline 3 & 2 & 11 & 3 \\
\hline
\end{tabular}


In other experiments ${ }^{19}$ the Scenedesmus have been kept at a steady state of Iight, temperature, $\mathrm{CO}_{2}$ pressure, etcog and constant $\mathrm{C}^{\mathrm{I}} \mathrm{O}_{2}$ specific activity until successive samplings of the suspension showed uniform labeling ("saturation") of all the common photosynthetic reservoirs (PGA, RDP, GMP, etico). The total $\mathrm{CO}_{2}$ pressure was then rapidly changed from $1 \% \mathrm{CO}_{2}$-in-air to $0.003 \%$ in air, all other environmental conditions, including the specific activity of $\mathrm{C}^{1} \mathrm{O}_{2}$, being kept constant. The conditions of this experiment were, therefore, similar to those used previously ${ }^{9}$ to study changing steady state exeept that $\mathrm{CO}_{2}$ pressure was changed instead of illumination. In the ease where $\mathrm{CO}_{2}$ pressure was lowered (Figure 6), the initial effects on the reservoir sizes of PGA and RDP were just the opposite of those observed when the illumination was stopped. Iowered $\mathrm{CO}_{2}$ pressure resulted in an increase in the reservoir size of $R D P$ and a decrease in that of PGA. After a time the reservoir of RDP passed through a maximum and dropped to a lower level but the new steady state RDP reservoir was now greater relative to that of PGA. The labeled glycolic acid present, though rather a small percentage of total activity, increased many fold when the $\mathrm{CO}_{2}$ pressure was lowered. The reservoir of giycolic acid increased much more slowly than that of the RDP and did not pass through a corresponding maximum, thus eliminating the possibility that most of the labeled glycolic acid was formed by thermal decomposition of RDP subsequent to killing of the cells. 


\section{Discussion}

\section{Origin of $P G A$}

It has been suggested that RDP is the compound which supplies the twocarbon atoms for the carboxylation reaction leading to PGA. ${ }^{9}$ If the reactions of these compounds are represented by
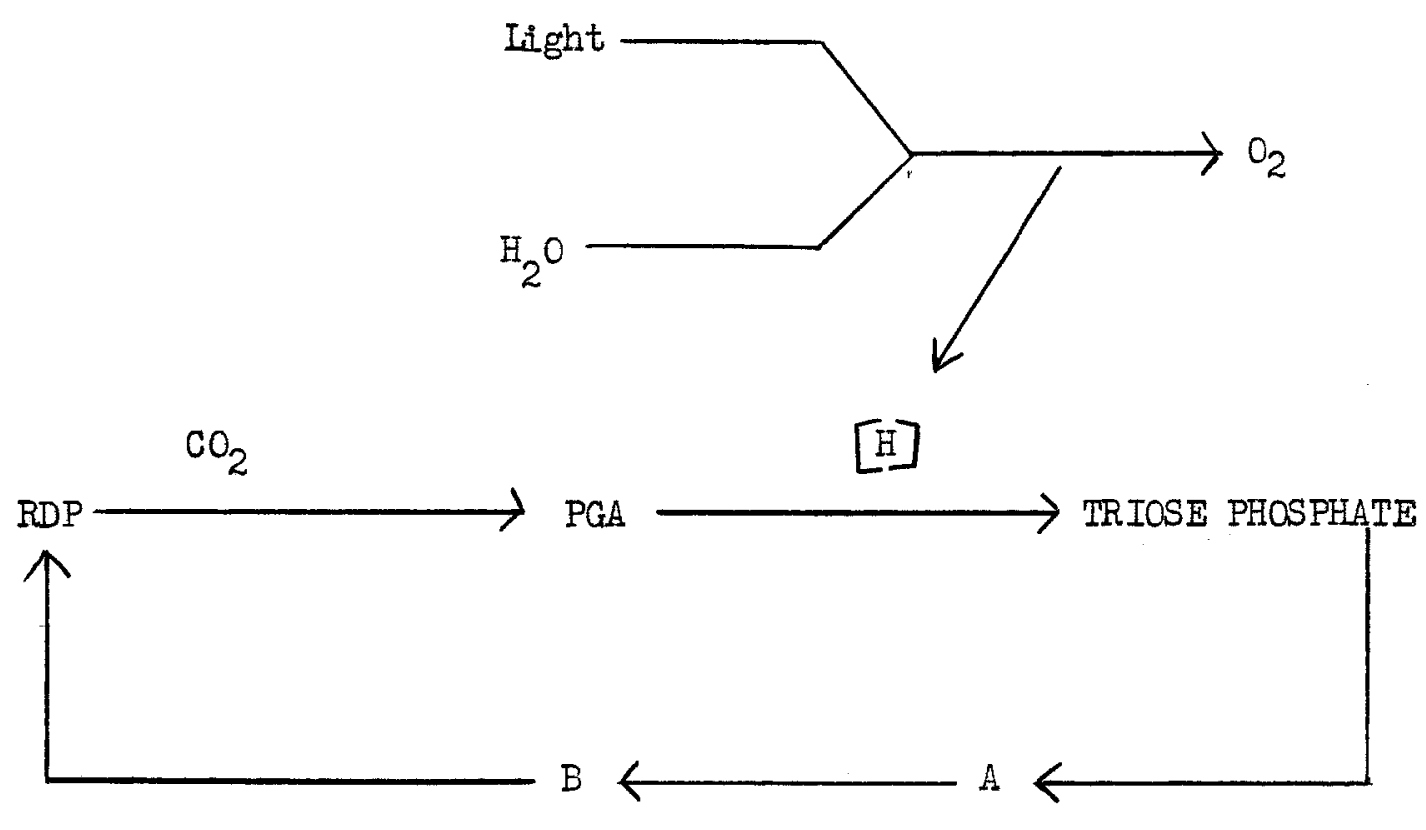

Sugar Rearrangements

then the initial changes in reservoir sizes which would accompany changes in light or $\mathrm{CO}_{2}$ pressure can be predicted. When the light is turned off, reducing power [H] decreases, so the reservoir at $\mathrm{PGA}$ would increase and that of $\mathrm{RDP}$ decrease. If $\mathrm{CO}_{2}$ pressure decreases, then the reservoir of $\mathrm{RDP}$ would increase and that of PGA would decrease. Both effects, as well as those opposite effects which would be expected to accompeny a resumption of light or increase in $\mathrm{CO}_{2}$ pressure, have been observed. These results support the proposal of a carboxylaw tion of RDP to give two molecules of $P G A$ or the reductive carboxylation to give one molecule of $P G A$ and one of phosphoglyceraldehyde as the first step in the path of carbon.dioxide reduction. 
It is also possible that the products of this aarboxylation might be phosphoglyceraldehyde and 3-phosphohydroxypyrutate. Ir this case subsequent reduction of the phosphohydroxypyruvate would give first $P G A$ and then phosphow glyceraldehyde. The reaction of phosphoglyceraldehyde with hydroxypyruvate to give ribulose monophosphate and $\mathrm{CO}_{2}$ has been demonstrated by Racker ${ }^{20}$ to take place under the influence of the transketolase enzyme. However, the in= crease in PGA concentration which is observed on stopping the illumination of photosynthesizing algae, 9 would probably not be seen if a reduction of hydroxypyruvate were required to form PGA since the reducing agent would presumably no Ionger be formed in the dark. Moreover, paper chromatographic analysis should detect either phosphohydroxypyruvate or its decarboxylation product, phosphoo glycolaldehyde, and neither have been found in our experiments. Wher $\mathrm{c}^{14}$. labeled hydroxypyruvate was administered to algae in this laboratory, the law beled acid was metabolized to give a variety of compounds, similar to those formed from labeled pyruvate or acetate, which were related more alosely to the tricarboxylic acid cycle and fat synthesis than to the compounds usually associated with carbon reduction in photosynthesis.

There remains the possibility thet the RDP first splits to give a three carbon molecule and a free two-carbon fragment which is then carbosylated. How ever, if the glycolic acid is an indication of the free two carbon fragment, then the observation that its increase in concentration (following reduction in $\mathrm{CO}_{2}$ pressure) is not as rapid as the increase in RDP concentration suggests that the $\mathrm{C}_{2}$ compound is not as closely related to the carboxylation reaction as the $\mathrm{RDP}$ 。 


\section{Origin of Ribulose Diphosphate}

If one considers the principal labeling at short times of $\mathrm{PGA}^{2}{ }^{2} \mathrm{RDP}, \mathrm{SMP}$ and the two hexose monophosphates ${ }^{2}$ as, respectively,
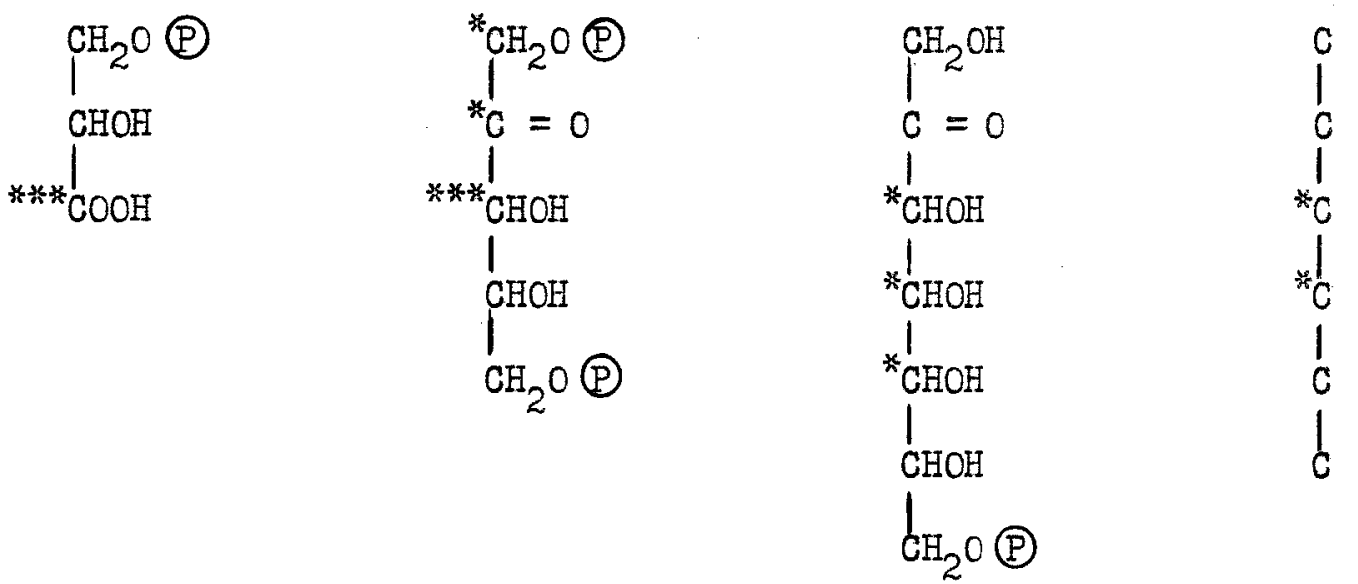

PGA

RDP

SMP

HMP

It appears that the ribulose is not derived entirely from a $C_{6} \rightarrow C_{1}+C_{5}$ split or a $\mathrm{C}_{7} \longrightarrow \mathrm{C}_{2}+\mathrm{C}_{5}$ split. No five carbon fragment of the hexose or the heptose molecules contains the same distribution of radiocarbon as ribulose. The combination of $\mathrm{C}_{3}$ with a labeled $\mathrm{C}_{2}$ fragment could account for the observed radioactivity. However, some mechanism for the labeling of the $\mathrm{C}_{2}$ fragment would be required. One such mechanism would be the breakdown of hexose simultaneously into three $\mathrm{C}_{2}$ fragments, $2 I$ and since carbon atoms 3 and 4 of hexose are labeled, a labeled $\mathrm{C}_{2}$ fragment might thus be obtained. To our knowledge there exists no precedent as yet for this type of reaction.

Another way of accounting for the observed distribution of radioactivity which seems quite plausible in view of the rapidly accumulating enzymatic evidence for the reverse reaction $20,22-24$ is the formation of ribulose from sedohepo tulose and triose. This reaction could result in the observed labeling in the 
following way:

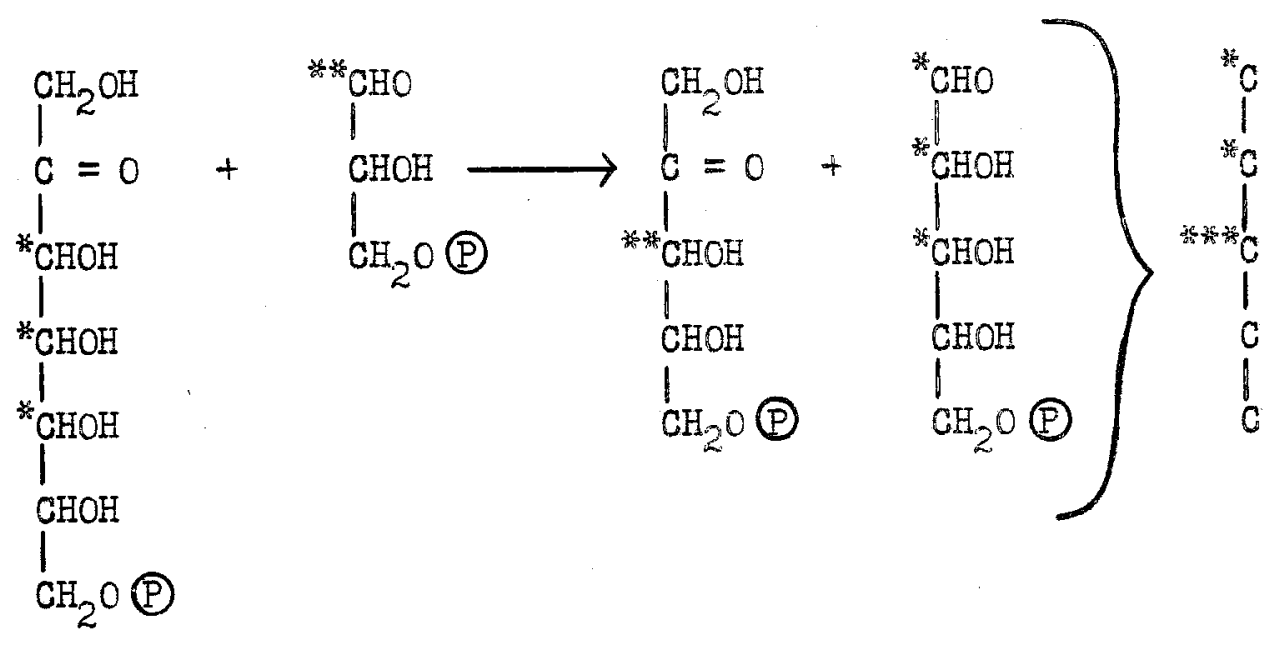

SMP

$$
\begin{array}{ccc}
\text { Phosphom } & \text { Ribulose } & \text { Ribose } \\
\text { glyceraldehyde } & \text { Monophosphate } & \text { Monophosphate }
\end{array}
$$

If the ribose-5-phosphate and ribulose-5-phosphate are then converted to RDP the resulting distribution of label would be that observed (carbon skeleton at right of reaction).

\section{Crigin of Sedoheptulose}

The degradation data appear to eliminate the possibility of formation of sedoheptulose by a simple $6+1$ or $5+2$ additions if we assume that no specirl reservoirs of pentose and hexose exist with distributions of radiogctivity different from those measured. A reverse of the reactions proposed abore for formation of RDP would require segregation of ribose and ribulose distributions as well as some other mechanism for labeling the ribose in the manner shown. It does seem likely that all the reactions involving rearrangements of sugars ard perhaps those involving reduction of $P G A$ as well are at least partialiy reo versible in the time of these experiments. If all these compourds are interm mediates in a cycle of carbon reduction, then auring steady state photosynthesis 
there will be a net "flow" of radiocarbon in the "forward" direction, but the possibility that the distribution of radiocarbon in later intermediates may reflect to some extent that of earlier intermediates cannot be entirely ignored. The condensation of a triose with a $C_{4}$ fragment would give the observed distribution if the $C_{4}$ fragment is labeled in the carbon atoms $I$ and $2:$

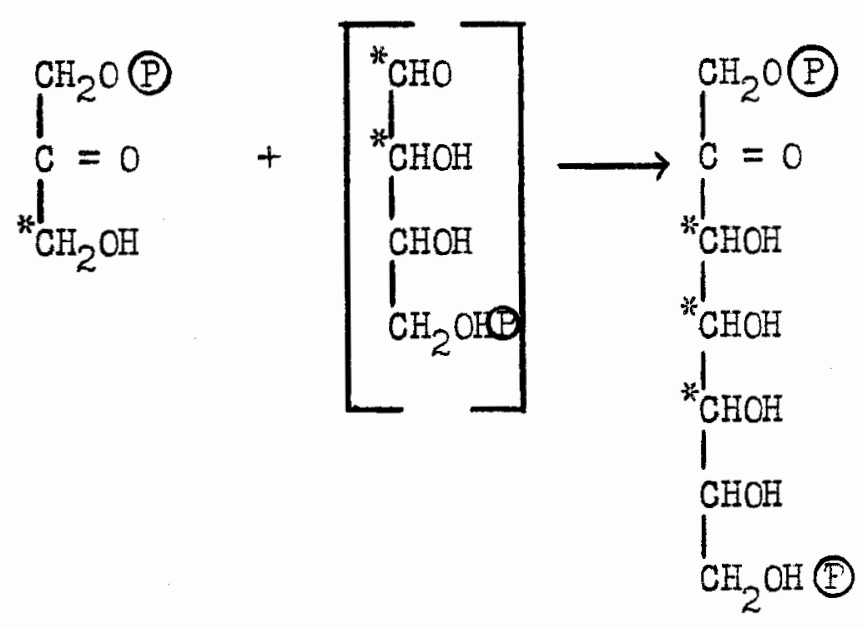

DHAP

Enzymatic evidence for this reaction and its reverse has been reported. 23,25

\section{Origin of the Four-Carbon Fragment}

Two possible modes of formation of the fourmarbon fragment with the above labeling are $a C_{1}+C_{3}$ addition, and $a_{6} \longrightarrow\left[C_{2}\right]+\left[C_{4}\right]$ split. The $C_{1}+C_{3}$ addition which leads to malic acid produces a $C_{4}$ fragment labeled in the two terminal positions.6 Therefore, the reduction of the dicarboxylic acid formed as a precursor to malic acia could not result in a $C_{4}$ fragment with the $c^{14}$ aiso tribution required for the formation of $3,4,5-C^{14}$-labeled sedoheptulose. The rapid introduction of radiocarbon into malic acid in earlier experiments ${ }^{4}$ can be accounted for if it is assumed that the reservoir size of malic acid, depleted during the air flushing prior to the addition of $\mathrm{HC}^{\mathrm{H}_{4}} \mathrm{O}_{3}^{-}$, was increasing after 
the adition of radiocarbon due to the increase in total $\mathrm{CO}_{2}$ pressure. AIso, after the carboxyl group of PGA and phosphoenolpyruric acid have become appreciably labeled, the malic acid is doubly labeled.

It is interesting to note that in the long texn "steady state" experiments in which the light was turned off 9 the malie acid concentration dropped when the light was turned off rather than incressing as PGA concentration increased. If malic acid were an indicatos of a four carbon intermediate in carbon reductiong the product of a second carboxylation, then one would expect its concentration to increase in the dark for two reasons. First, there no longer is reducing power which would reduce the carboxylation product to sugar if this product were an intermediate in $\mathrm{CO}_{2}$ reduction. Second, the rote of formation of malic acid should increase since this rate depends on the $\mathrm{CO}_{2}$ concentration (which remains constant), and the concentration of phosphosnolpyruvid scid (which increases paralleling the PGA corentration. The decrease in malie asid concentration could be easily explained on the basis of the proposed light irhibition of pyruvic acid axidation. 9 The cessation of illumination should permit increased pyruvic acid oxidation, thus providing mose acetylo6oA, which cen react with oxaloacetic acid derived from malic acid.

It is possibie that there is disferect "second carborylation" $\left(C_{1}+C_{3}\right)$ leading eventually to a fourasaroon fragment which can react with triose to give sedoheptulose, but there zeems to be no evidence whetever for such a reaction at present. Moreover, such a reaction should lead in short times to a fouro carbon fragment somewhet more labeled in the terminal carbon position than in the second carbon position due to dilution of the carbon introdueed in the first carboxylation reaction by the PGA and triose reservoirs. This is not the ease in fact in the rery shortest times the terminal carbon position of the hypo theticel $C_{4}$ fragment (carbon four of sadohepturose) is actugliy less labeled. 
than the second position, at least in the soy bean experiments.

The most likely source of the $\mathrm{C}_{4}$ fragment seems to be a $\mathrm{C}_{6} \longrightarrow\left[\mathrm{C}_{4}\right]+\left[\mathrm{C}_{2}\right]$ split. Trioses could then react with $\left[\mathrm{C}_{4}\right]$ and $\left[\mathrm{C}_{2}\right]$ to give sedoheptulose and ribulose, respectively. One possible formulation of these reactions would be the following:
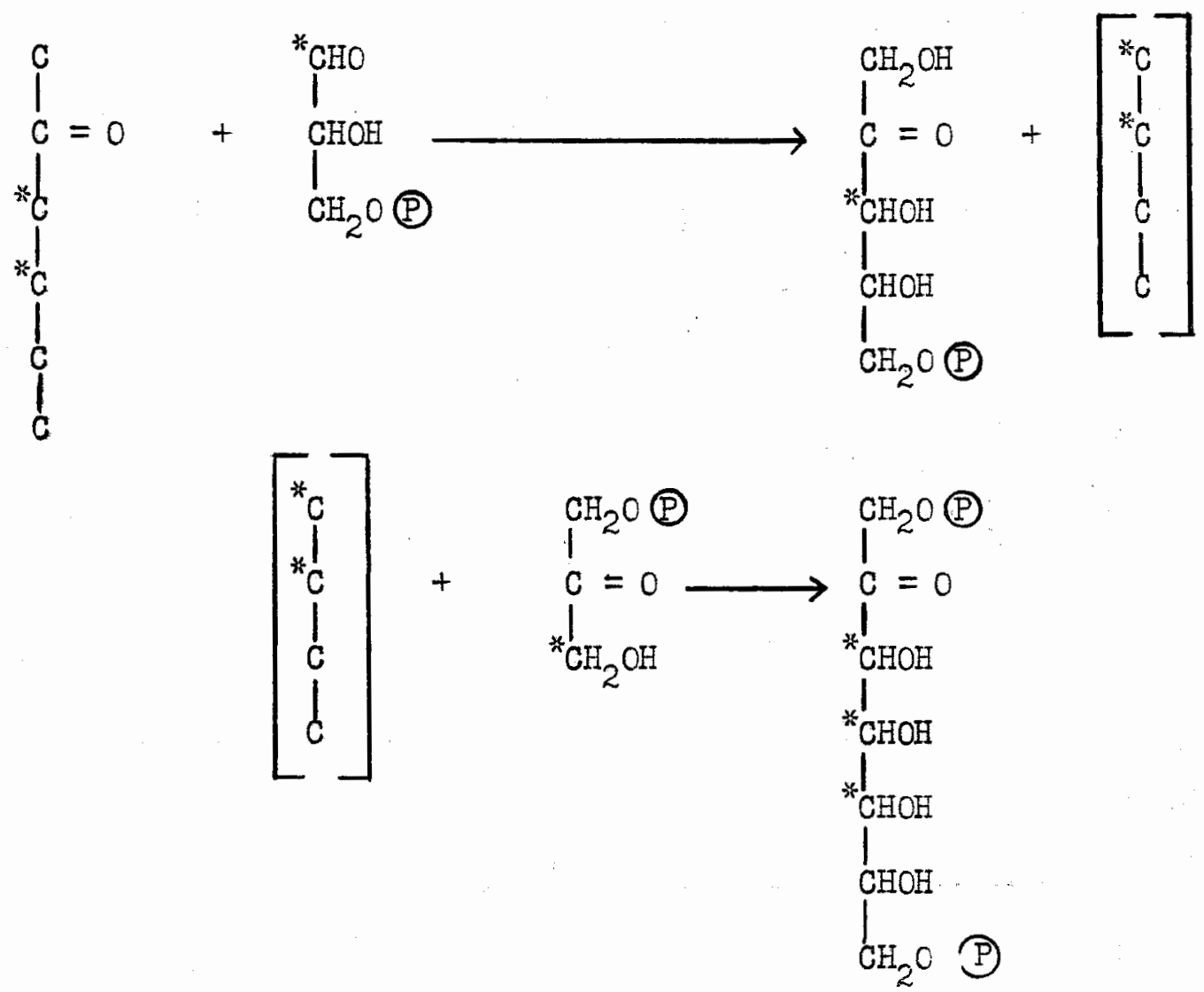

The first reaction as written above would be a transketolase reaction of the type reported by Racker, et al, ${ }^{20}$ who found that this enzyme splits ribulose5-phosphate, leaving glyceraldehyde-3-phoswhate and transferring the remaining two-carbon atoms to an acceptor aldehyde phosphate of 2,3 , or 5 carbon atoms. No mention was made of the effect of transketclase on ribose-5-phosphate with erythrose4-phosphate which would result in the formation of fructose phosphate by a reaction 
which is just the reverse of the $\mathrm{C}_{6} \longrightarrow\left[\mathrm{C}_{2}\right]+\left[\mathrm{C}_{4}\right]$ split written above. ${ }^{26}$

The labeling of carbon number 4 in sedoheptulose observed in the case of the very short periods of photosynthesis with soybean leaves seems to cast some doubt on the $\mathrm{C}_{6} \longrightarrow\left[\mathrm{C}_{2}\right]+\left[\mathrm{C}_{4}\right]$ split unless one can assume that the $\mathrm{C}_{6}$ which splits is itself not symetrically labeled at the shortest times, due to different specific activities of the two trioses which react to give hexose:

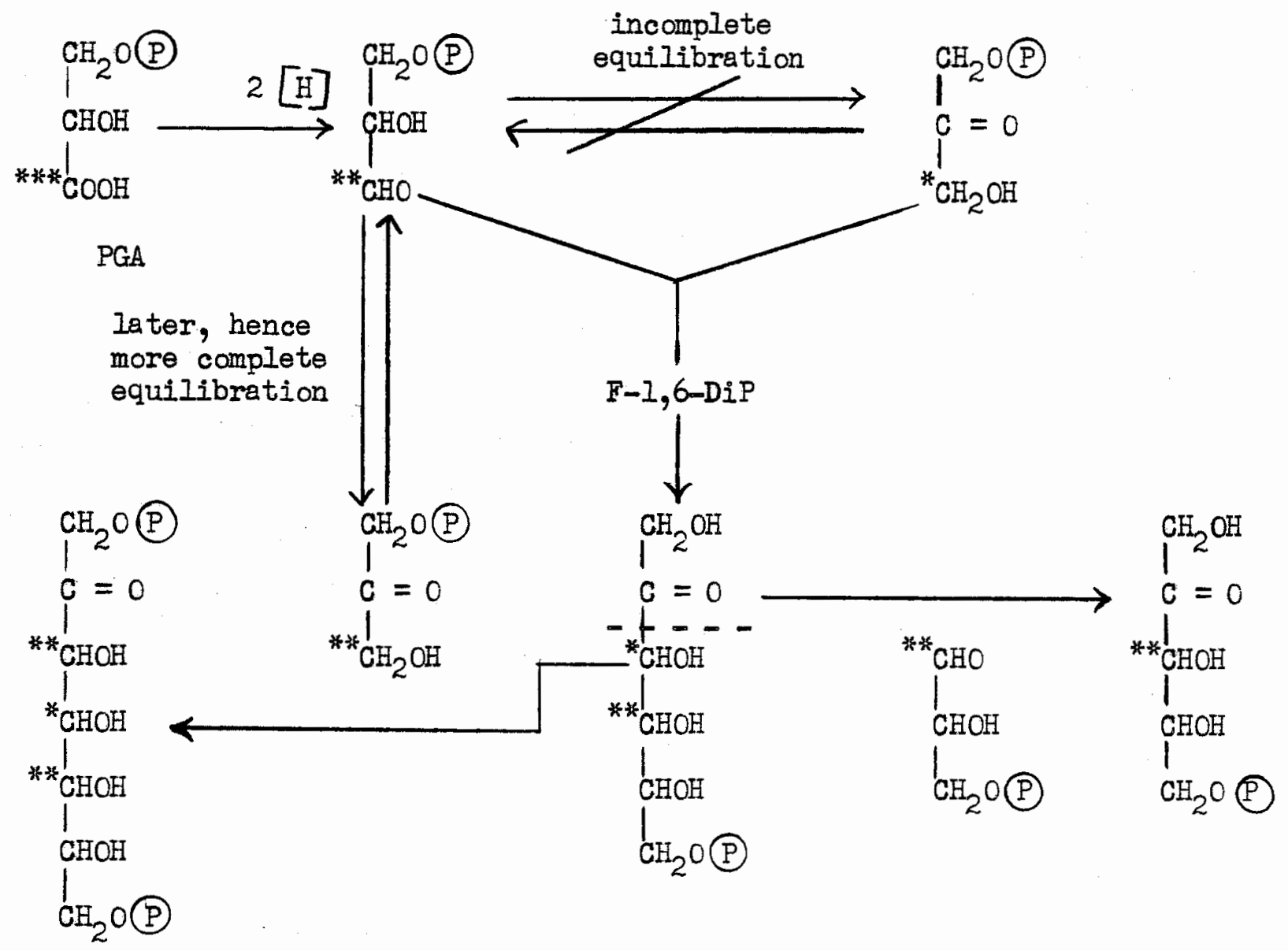

Degradation of fructose from the 0.4 and 0.3 sec. experiments showed no significant difference between the two halves of fructose. It is quite possible, however, that the differences in denaturation rates of various enzymes mentioned earlier may influence the results in these short times. 
Combining these reactions with others already proposed we have the following cyclic path of carbon reduction during photosynthesis. The carbon fragments specified only by the number of carbon atoms in their chains are all at the sugar level of reduction:

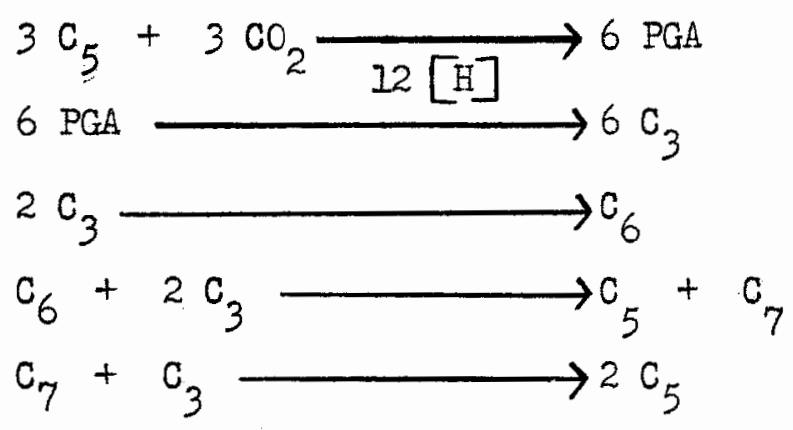

The net reaction for each turn of the cycle is

$$
12[\mathrm{H}]+3 \mathrm{CO}_{2} \longrightarrow \mathrm{C}_{3} \mathrm{H}_{6} \mathrm{O}_{3}+3 \mathrm{H}_{2} \mathrm{O}
$$

The operation of this cycle is illustrated in Figure 70

\section{Energetics of the Carbon Reduction Crcle}

That the enzymatic rearrangements of sugars requires no additional supply of energy in the form of ATP or other sources seems to be indicated by the experiments with isolated and partialiy purified enzyme preparations in which such rearrangements have been carried out without the addition of energy donors. The free energy change of the carboxylation reaction can be roughly estimated. Estimating the free energy of formation of ribose as about $-180 \mathrm{Kcal}$. and assuming an energy difference between ribose-5-phosphate and RDP equal to that between GMP and fructose diphosphate, the free energy change for the reaction below is about -7 KcaI. 27,28 


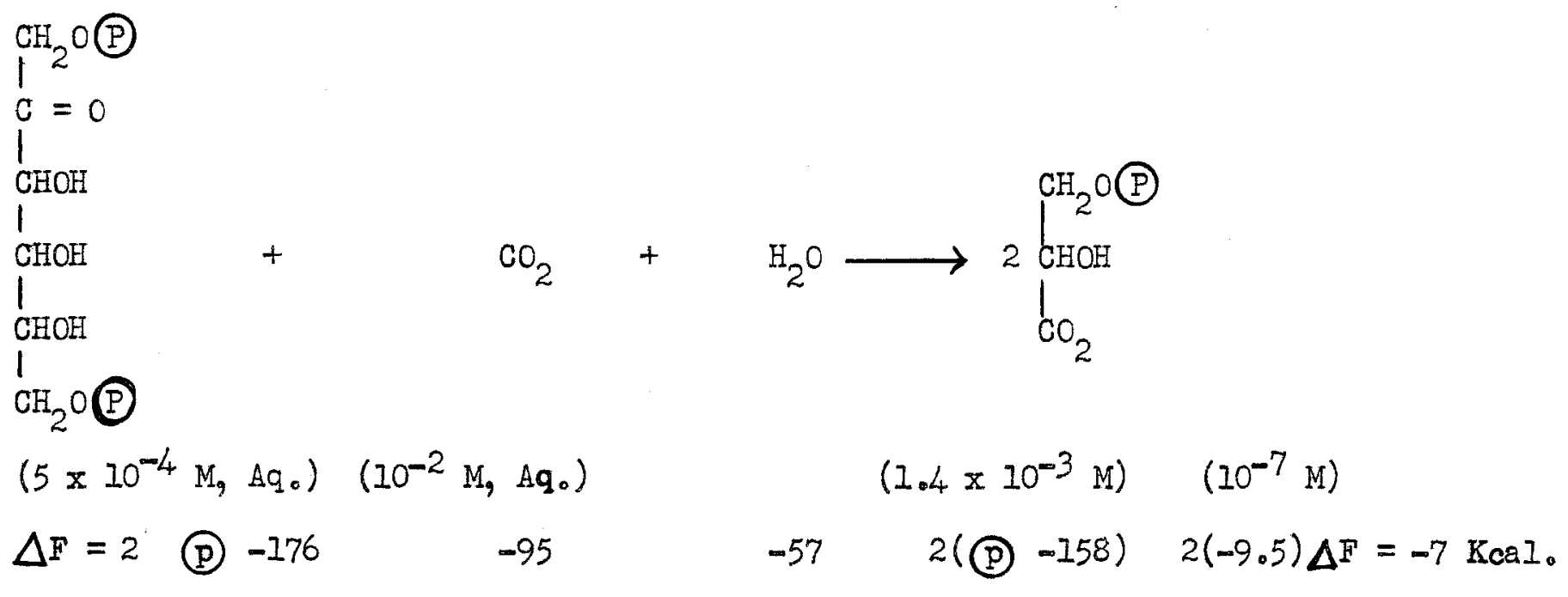

In the above calculation the concentrations of RDP and PGA measured with Scenedesmus during photosynthesis with $1 \% \mathrm{CO}_{2}{ }^{9}$ are used. The mechanism of the reaction may consist of the addition of $\mathrm{CO}_{2}$ to the 2,3-enediol sugar formed by enolization of the RDP. The intermediate compound would be 2-carboxypentulose-3. The free energy for the formation of the ion of this acid and $\mathrm{H}^{+}$(pH 7) from $\mathrm{CO}_{2}$ and $\mathrm{RDP}$ is estimated as zero when the concentration of the intermediate acid is $10^{-9} \mathrm{M}$. Subsequent hydrolytic splitting of this compound to two molecules of PGA and another hydrogen ion would proceed with a free energy change of -7 Kcals o

The energy required to maintain the operation of the proposed carbon reduction cycle might be supplied entirely in the reduction of PGA to triose phosphate. If this reduction were accomplished by a reversal of the enzymatic reaction usually written, each "turn" of the cycle would be represented by three times the reaction:

$$
\text { A. } \begin{aligned}
& 2 \mathrm{DPN}\left[\mathrm{H}_{2}\right]+2 \mathrm{ATP}+\mathrm{CO}_{2} \longrightarrow\left\{\mathrm{CH}_{2} \mathrm{O}\right\} \\
&+2 \mathrm{DPN}+2 \mathrm{ADP}+2 \mathrm{P}+\mathrm{H}_{2} \mathrm{O}
\end{aligned}
$$

This is the sum of the reactions: 

B. $2\left[\mathrm{DPN}\left[\mathrm{H}_{2}\right]+1 / 2 \mathrm{O}_{2} \longrightarrow \mathrm{DPN}+\mathrm{H}_{2} \mathrm{O}\right]$
$\Delta F=-101$
C. $2[\mathrm{ATP} \longrightarrow \mathrm{ADP}+\mathrm{P}]$
$\Delta F=-2 I$
D. $\mathrm{CO}_{2}+\mathrm{H}_{2} \mathrm{O} \longrightarrow \mathrm{O}_{2}+\mathrm{CH}_{2} \mathrm{O}$
$\Delta F=+116$

The efficiency of the transfer of energy of reactions $B$ and $C$ to reaction $D$ is $116 /(21+101)=0.96$.

However, additional energy might be supplied to the operation of the cycle by phosphorylation reactions in which additional molecules of ATP are required. One such reaction may well be the phosphorylation of ribulose monophosphate to give ribulose diphosphate. In this case, one additional molecule of ATP would be required per molecule of $\mathrm{CO}_{2}$ reduced. The efficiency of the net reaction (A') would then be $116 / 132.5=0.88$.

$\mathrm{A}^{\prime} 2 \mathrm{DPN}\left[\mathrm{H}_{2}\right]+3 \mathrm{ATP}+\mathrm{CO}_{2} \longrightarrow \mathrm{CH}_{2} \mathrm{O}+2 \mathrm{DPN}+3 \mathrm{ADP}+3 \mathrm{P}+\mathrm{H}_{2} \mathrm{O}$

The overall efficiency of photosynthesis would be the product of 0.96 or 0.88 and the efficiency of the process by which water is photolyzed to give axygen with the production of reducing power, followed by the conversion of the energy of this reducing power to $\mathrm{DPN}\left[\mathrm{H}_{2}\right]$ and $A T F$.

If the mechanism for photolysis of water involves thioctic acid, as has been proposed, 29 the energetics of the photochemical and following steps can be esw timated:

E。<smiles>CC([SeH])CC[C@H](C)CC[SnH3]</smiles>

(where the symbol represents the side chain: $-\left(\mathrm{CH}_{2}\right) \mathrm{CO}_{2} \mathrm{E}$ ) 
F. $2 \overbrace{\mathrm{SH}} \rightarrow \overbrace{\mathrm{SH}} \mathrm{SHH}_{\mathrm{SH}}+\overbrace{S \rightarrow \mathrm{H}_{2} \mathrm{O}}+1 / 2 \mathrm{O}_{2}$

In this process, two quanta are required for each dithiol molecule formed. The stored energy is the sum of the energies of the two following half reactions:

G.

$$
\mathrm{H}_{2} \mathrm{O} \longrightarrow 2 \mathrm{H}^{+}+2 \mathrm{e}^{-}+\mathrm{I} / 2 \mathrm{O}_{2}
$$

$\Delta \mathrm{F}=+37.5 \mathrm{Kcal}$.

H.

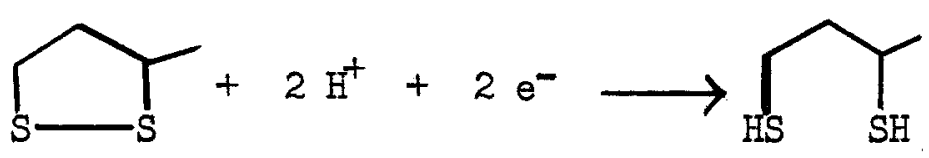

$$
\begin{aligned}
E & =-0.3 \mathrm{v} .30 \\
\Delta F & =+13.8 \mathrm{Kcal} .
\end{aligned}
$$

which is

I. $\mathrm{H}_{2} \mathrm{O}+\overbrace{\mathrm{S} \longrightarrow \mathrm{S}} \stackrel{(2 \mathrm{~h} \boldsymbol{\nu})}{\longrightarrow} \overbrace{\mathrm{HS}}+1 / 2 \mathrm{O}_{2} \quad \Delta \mathrm{F}=51.3 \mathrm{Kcal}$.

Since the energy available from two light quanta at $7000 \AA$ is $2 \times 40.7$ or 81.4 Kcal., the efficiency of this process would be 51.3/81.4 $=0.63$.

If Co-I is used in the reduction of PGA, the reduced coenzyme could be formed with high efficiency from the dithiol

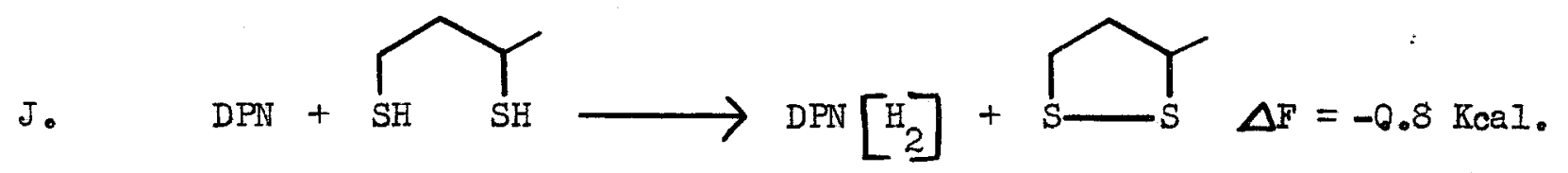

The required ATP could be formed in some way by oxidation of or DPN[[- $\left.\mathrm{H}_{2}\right]$ by an energetic coupling of the following reactions:

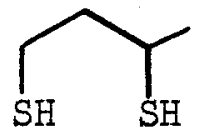
K。
$\mathrm{DPN}\left[\mathrm{H}_{2}\right]+$
$1 / 2$
$\mathrm{O}_{2} \longrightarrow \mathrm{DPN}+\mathrm{H}_{2} \mathrm{O}$
$\Delta F=-50.5 \mathrm{Kcal}$. 
I. $\quad A D P+P \longrightarrow A T P \quad \Delta F=+10.5$ Keal.

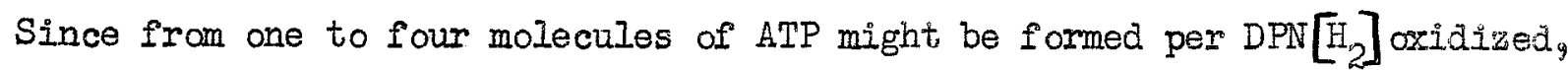
a wide range of efficiencies would be possible. A value of three has been sugw gested $^{3 I}$ and if this is used, the resulting coupling reaction could be written:

Mo $\quad \mathrm{DPN}\left[\mathrm{H}_{2}\right]+1 / 2 \mathrm{O}_{2}+3 \mathrm{ADP}+3 \mathrm{P} \longrightarrow \mathrm{DPN}+\mathrm{H}_{2} \mathrm{O}+3 \mathrm{ATP}$

Multiplying reaction $J$ by 3 and combining with reaction $M$ we have N.

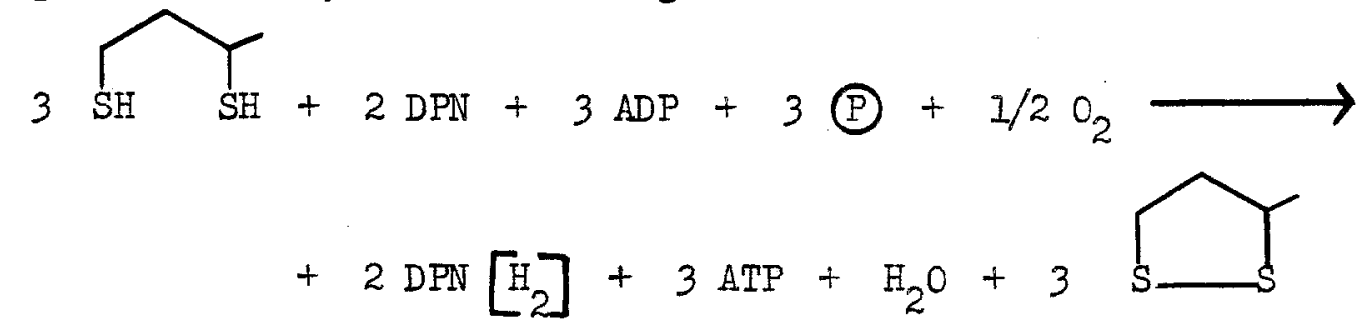

in which the stored energy is $132.5 \mathrm{Kcal}$, and the energy expended is times reaction $H=154$ Kcals. The efficiency of the energy transfers represented by reaction $\mathbb{N}$ is then $132.5 / 154=0.86$.

Combining the efficiencies of reactions $A, I_{9}$ and $\mathbb{N}$ resuits in a calculated overall efficiency for photosynthesis of $0.88 \times 0.63 \times 0.86=0.48$. Since the mechanism outlined above would require six quanta for each molecule of carbon dioxide reduced (two quanta for each molecule of dithiol used in reaction $\mathbb{N}$ ) this efficiency can be obtained directly from the energy of these quanta (244 $\mathrm{Kag} \mathrm{I}_{0}$ ) and the energy of reaction $D: 116 / 244=0.48$.

Higher apparent efficiencies would be obtained at low light intensities where the dark internal conversion of prior storage products (involving no net uptake of oxygen or evolution of $\mathrm{CO}_{2}$ ) would supply appreciable amounts of ATP, DPNH, reduced thioctic acid and possibly intermediates of the $\mathrm{O}_{2}$ erolution shain as well. 27 
Since reaction I as written stores only $51.3 \mathrm{Kcal}$. of $81.4 \mathrm{Kcal}$. available, it is possible that some mechanism may exist for the storage of some of this energy in the form of either additional reducing power or high energy phosphate. In this case, the overall efficiency would be higher.

\section{Other Biological Evidence}

The interconversions of the five-, and seven-carbon sugars are being investigated by several laboratories. The postulated cyclic reactions which our data suggest are consistent with the observations of these various groups. Both the work of Axelrod, et al en $^{22}$ with spinach preparations and the results reported by Dische and Pollaczek 32 with hemolysates demonstrate the sequence ribuse phosphate $\longrightarrow$ heptulose phosphate + triose phosphate $\longrightarrow$ hexose phosphate.

Recently studies have been made of the distribution of $\mathrm{c}^{1 / 4}$ in products resulting from conversion of I-c $C^{1 / 4}$ labeled pentoses. Neish ${ }^{33}$ has studied the products of bacterial metabolism of several pentoses while Wolin, et al. ${ }^{34}$ investigated the products of enzymatic conversion of ribose-5-phosphate. In both cases, the distribution of radioactivity in the products could be accounted for by a reversal of the reactions herein suggested earlier, although a limited number of other interpretations of their data are possible.

\section{Summarxy 35}

Photosynthesizing plants have been exposed to $\mathrm{C}^{\mathrm{H}_{\mathrm{H}}} \mathrm{O}_{2}$ for short periods of time $(0.4$ to 15 sec.) and the products of carbon dioxide reduction analyzed by paper chromatography and radioautography.

Methods have been developed for the degradation of ribulose and sedoheptulose. These sugars, obtained as their phosphate esters from the above $\mathrm{c}^{\mathrm{I}_{4}} \mathrm{O}_{2}$ 
exposures and from other experiments, have been degraded and their distribution of radiocarbon determined.

The distribution of radiocarbon in these sugars, and other data, indicate that sedoheptulose phosphate and ribulose diphosphates are formed during photosynthesis from triose and hexose phosphates, the latter being synthesized, in turn, by the reduction of 3-phosphoglyceric acid.

Further evidence has been found for the previously proposed carboxylation of ribulose diphosphate to phosphoglyceric acid. Free energy calculations indicate this step would proceed spontaneously if enzymatically catalyzed.

The efficiency of this cycle for reduction of $\mathrm{CO}_{2}$ to hexose would be 0.9 if the reduction of each molecule of PGA requires the concurrent conversion of one molecule of ATP and one of DPN (red) to ADP, inorganic phosphate, and DPN (ox.). This mechanism, together with an assumed mechanism for the photolysis of water, would lead to an efficiency of about 0.5 for the overall photosynthetic reaction and a requirement of about six quanta of light per molecule of $\mathrm{CO}_{2}$ reduced to carbohydrate. 


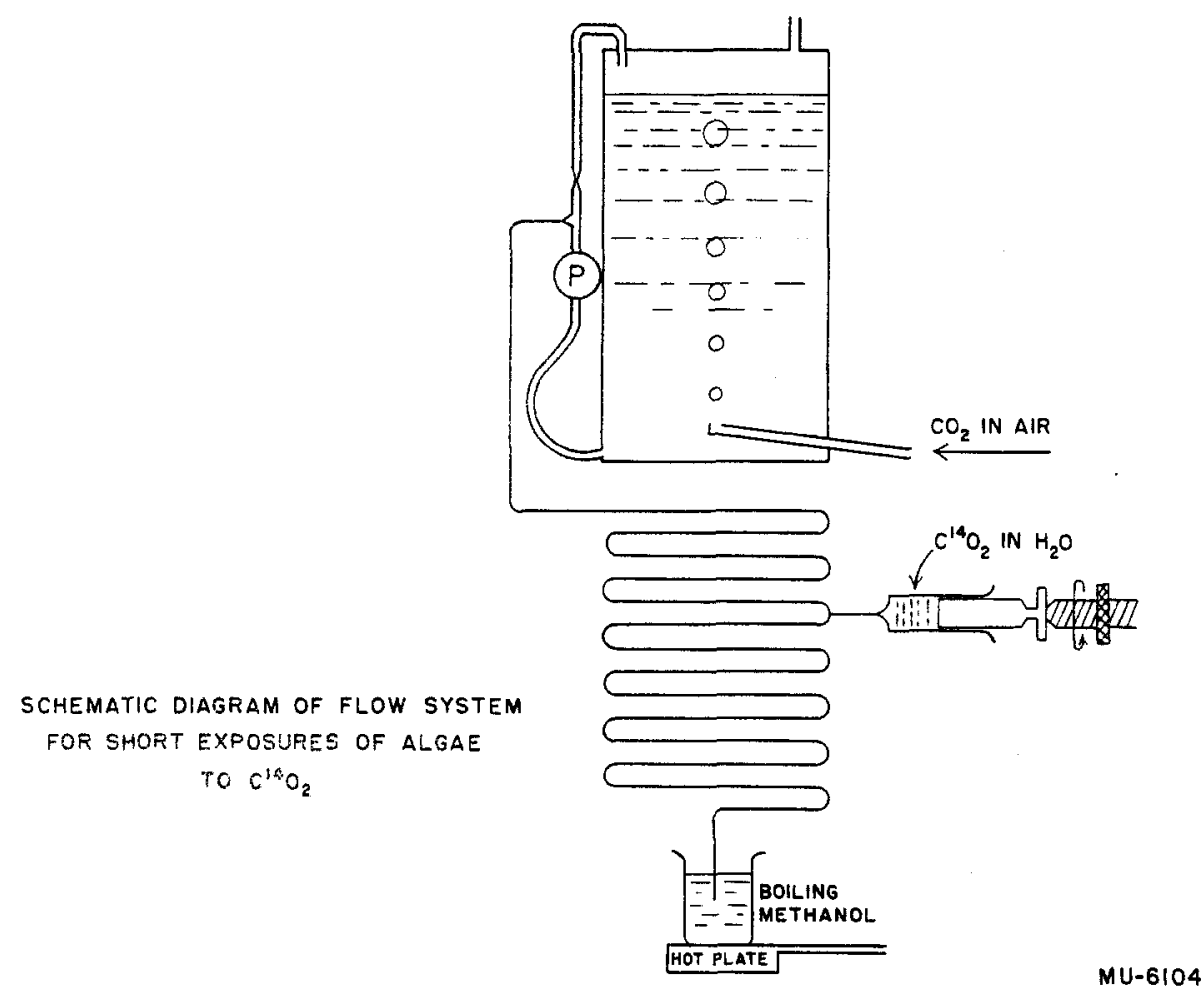

Fig. 1 
RADIOACTIVITY INCORPORATED IN "STEADY STATE" PHOTOSYNTHESIS WITH SCENEDESMUS

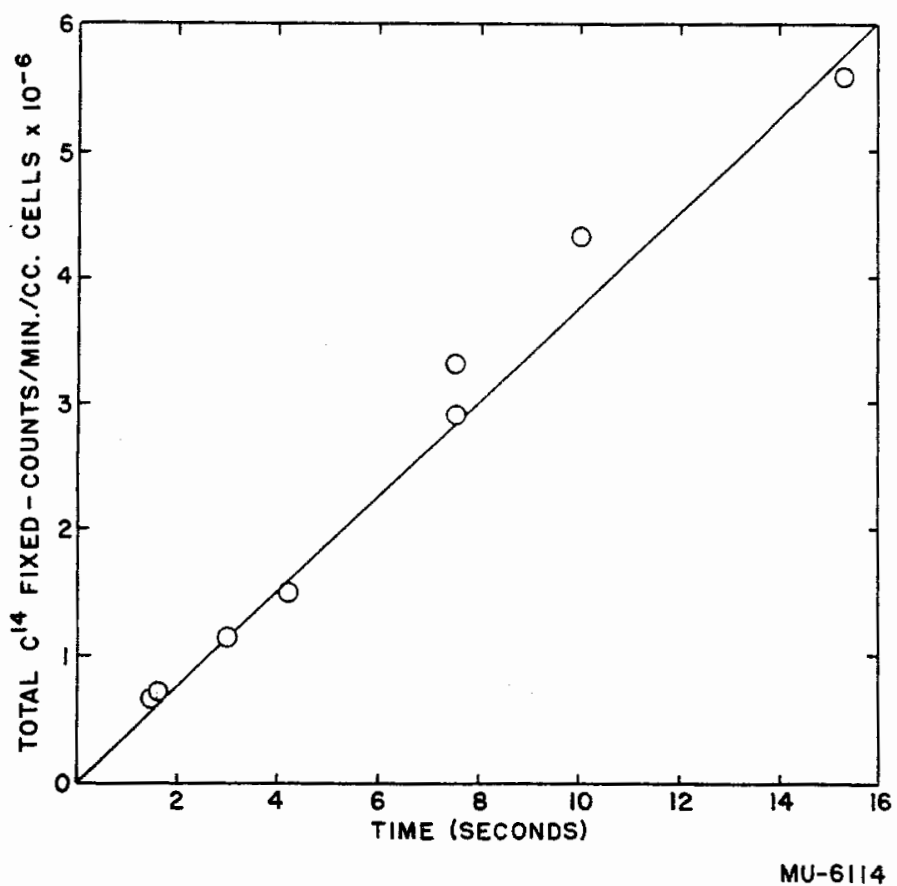

Fig.? 
DISTRIBUTION OF RADIOACTIVITY

AMONG COMPOUNDS FORMED DURING

"STEADY STATE" PHOTOSYNTHESIS WITH SCENEDESMUS

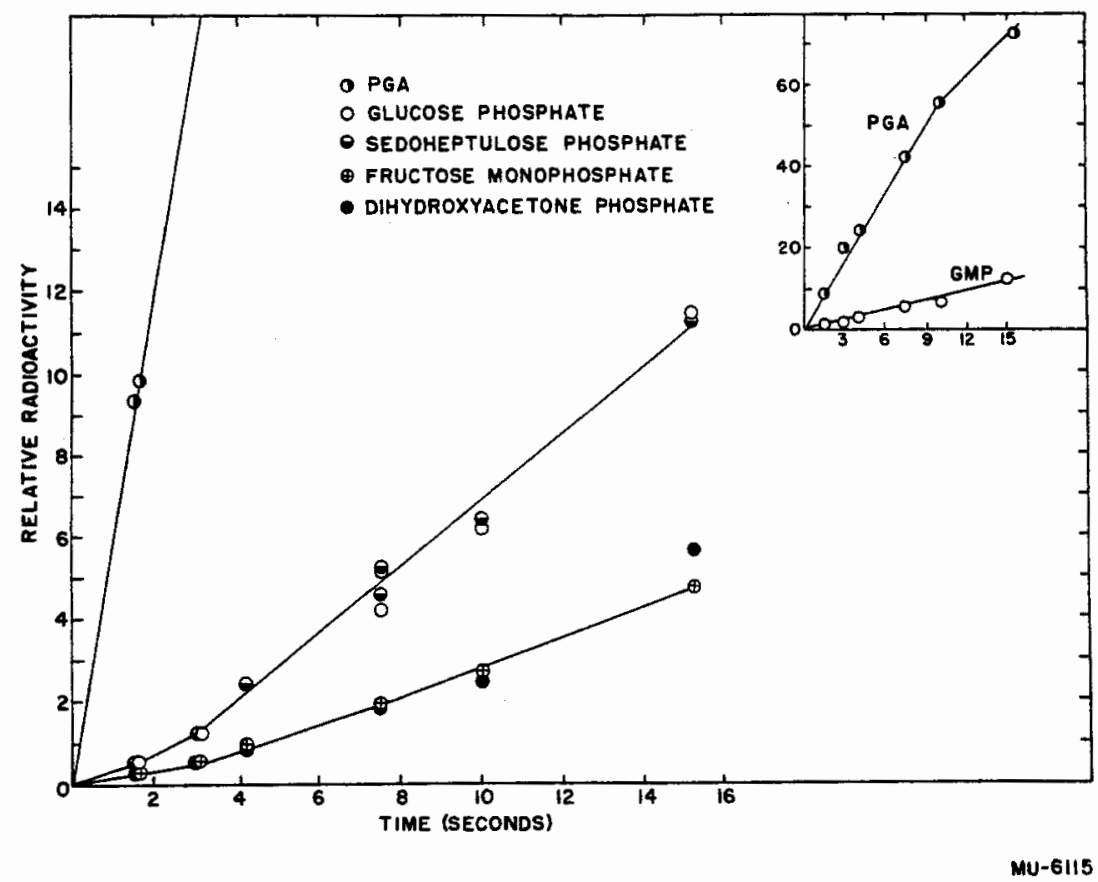

Fig. 3 


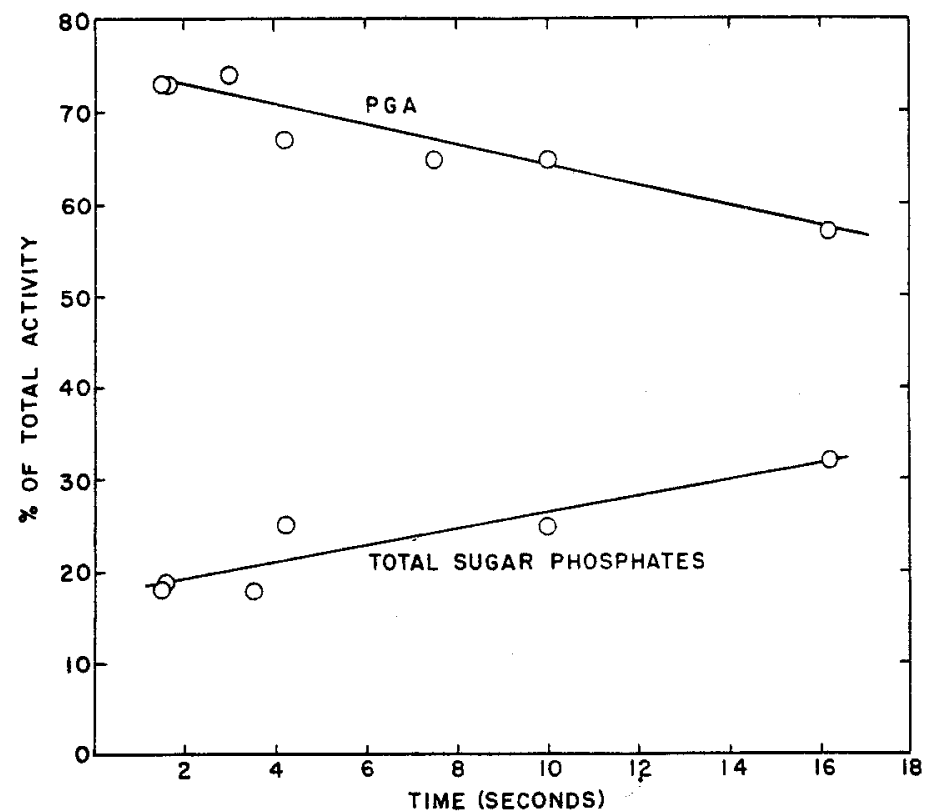

DISTRIBUTION OF ACTIVITY IN

$M U-6103$ "STEADY STATE" SCENEDESMUS

Fig. 4 
DISTRIBUTION OF RADIOACTIVITY INCORPORATED

in "steady state" photosynthesis WITH SCENEdesmus

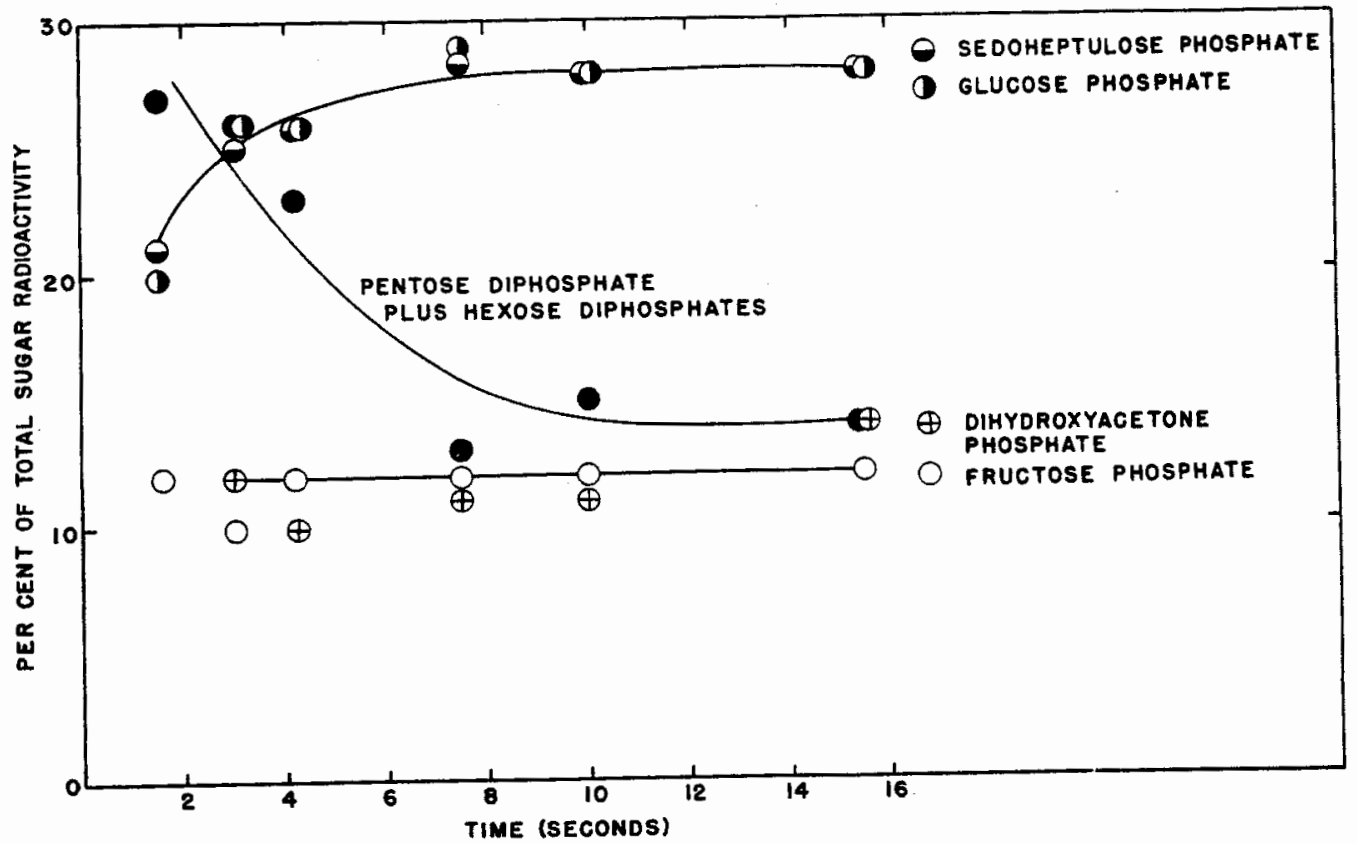

MU-6116

Fig. 5 


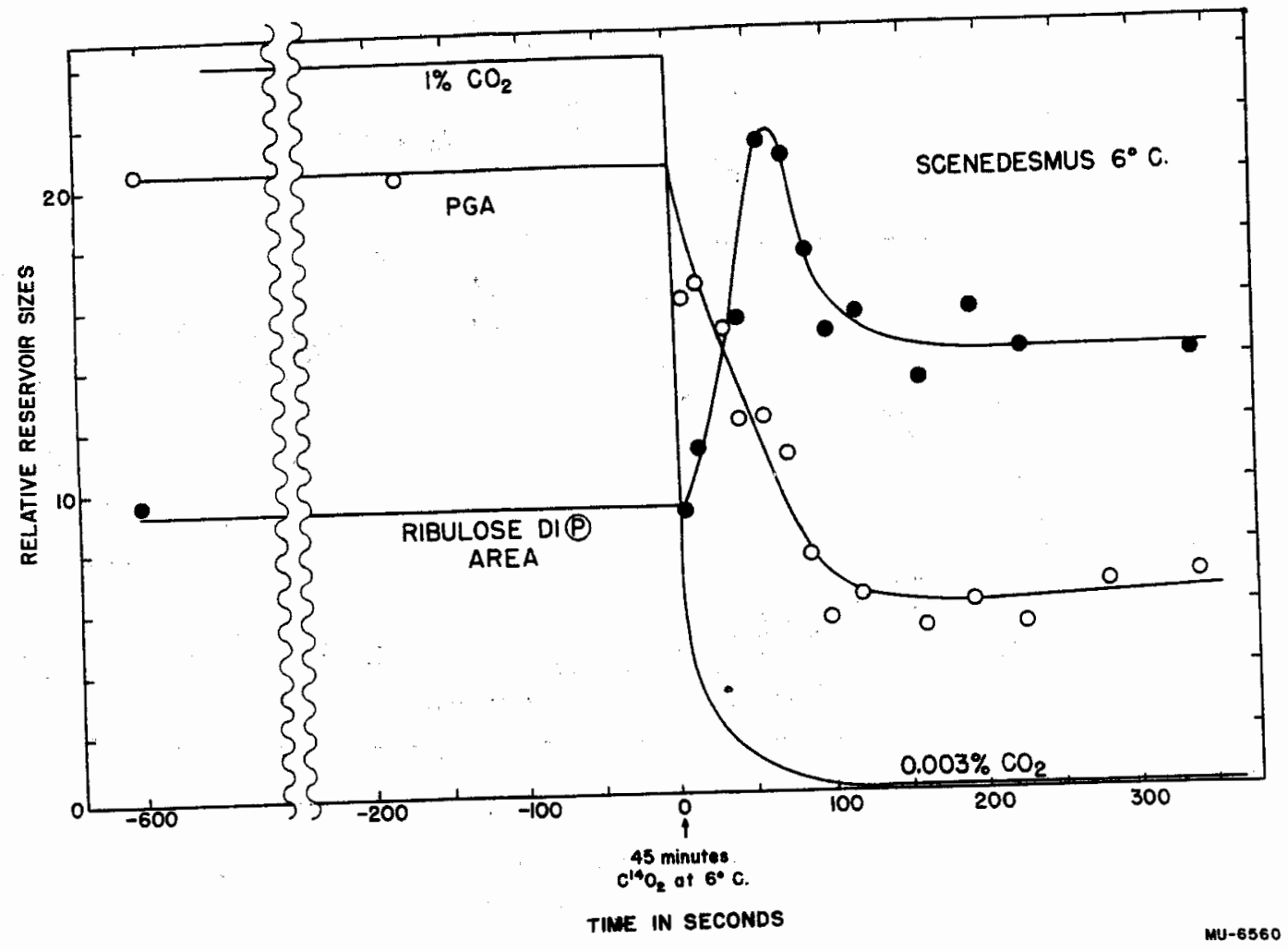




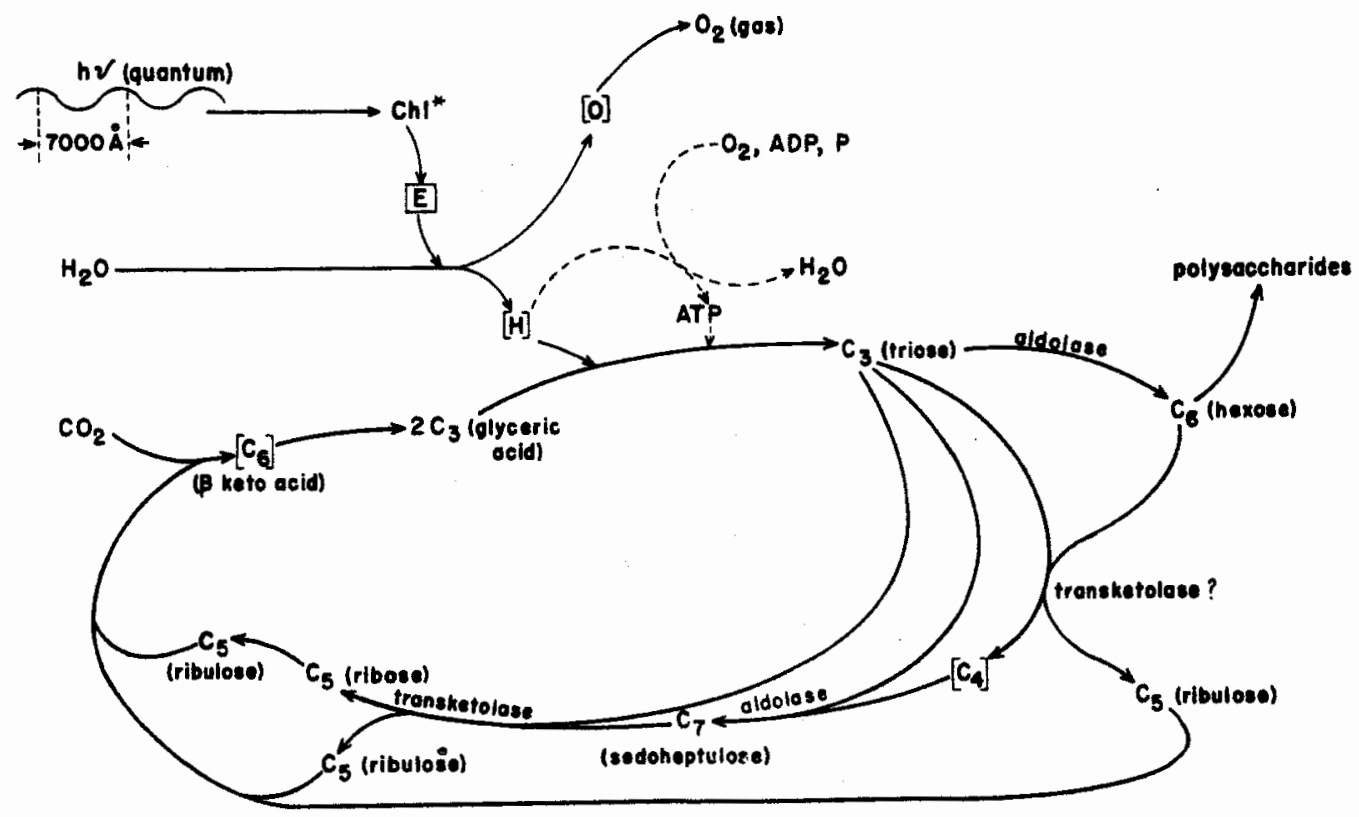

PROPOSED CYCLE FOR CARBON REDUCTION

IN PHOTOSYNTHESIS

MU-6600 


\section{References}

(I) The work described in this paper was sponsored by the U.S. Atomic Energy Commission.

(2) M. Calvin "The Harvey Iectures," 1950-51, Charles C. Thomas Publishing Company, page 218 .

(3) The following abbreviations will be used throughout this paper: PGA, phosphoglyceric acid; DHAP, dihydroxyacetone phosphate; FMP, fructose monophosphate; GMP, glucose monophosphate; SMP, sedoheptulose monophosphate; RDP, ribulose diphosphate; ADP, adenosine diphosphate, ATP, adenosine triphosphate; DPN, diphosphopyridine nucleotide (Coenzyme I), oxidized form; $\operatorname{DPN}\left[\mathrm{H}_{2}\right]$, diphosphopyridine nucleotide, reduced form.

(4) A. A. Benson, S. Kawaguchi, P. M. Hayes and M. Calvin, J. Am. Chem. Soc.g 74, 4477 (1952).

(5) A. A. Benson, et ale, "Photosynthesis in Plants," Iowa State College Press, Ames, Iowa (1949), page 381.

(6) D.W. Racusen and S. Aronoff, Arch. Biochem. Biophys., L2, 25 (1953).

(7) J. A. Bassham, A. A. Benson and M. Calvin, J. Biol. Chem., 185, 781 (1950).

(8) A. A. Benson, et al., J. Biol. Chem., 196, 703 (1952).

(9) Mo Galvin and Peter Massini, Hxperientia, $\underline{8}, 445$ (1952).

(10) A. A. Benson, et aI, J. Am. Chem. Soc., 72, 1710 (1950).

(1I) W. T. Haskins, R. N. Hann and C. S. Hudson, J. Am. Chem. Soc., 68, 1766 (1946).

(12) Y. J. Topper and A. B. Hastings, J. Biol. Chem., 179, 1255 (1949).

(13) G. Frederick Smith, "Cerate Oxidimetry," G. Frederick Smith Chemical Company, Columbus, Ohio (1942). 
(u) he are Indebted to Prof. John C. Speck, Jx., of Michigan State College, Jast Iansing; Michigan, for valuable date and suggestions regarding the use of cerate in these oxidations.

(I5) (a) I. C. Stewart, N. K. Richtmyer and C.S. Hudson, J. Am. Chem. Soc., 74, 2206 (1952. (b) We wish to express our appreciation to Dr. R. clinton Fuller for his development of the microfermentation.

(26) We wish to thank Dr. N. K. Richtmyer for his generous gift of crystalline guioheptulosan.

(I7) J. W. Pratt, N. K. Richtmyer and C.S. Hudson, J. Am. Chem. Soc., Ik, 2200 (1952).

(18) A. A. Benson, Zeit. f. Elektrochem., 56, 848 (1952).

(19) A. T. Wilson, Thesis, to be submitted as partial fulfillment of requirements for the degree of Doctor of Philosophy, University of California.

(20) I. Racker, G. de Ia Haba and I. G. Ieder, J. Am. Chem. Soc., 75, 1010 (1953).

(2I) I. Gaffron, I. W. Fager and J. L. Rosenberg, "Carbon Dioxide Fixation and Photosynthesis," Symposia of the Society for Experimentaz Biology (Great Britain), Vol. V, Cambridge University Press (1951).

(22) E. Lxeirod, R. S. Bandurski, C. M. Greiner and R. Jang, J. Biol. Chem., 202, 619 (1953).

(23) E. L. Iiomecker and P.Z. Smyrniotis, J. Am. Chem. Soc., Z4, 2123 (1952).

(24) E. I. Horecker and F. Z. Smyrniotis, J. Am. Chem. Soc., 75, 1009 (1953).

(25) E. I. Florecke: and P. Z. Smyrniotis, J. Am. Chem. Soc., 75, 2021 (1953).

(26) Since thise wes mitten, a private commuication from Dr. Racker has informed us that he hes observed this reection with $F-6-F$. 
(27) The internal energy of the $-\mathrm{PO}_{3} \mathrm{H}^{-}$group, exclusive of the energy of bonding to the remairider of the molecule is here denoted by (P) and assumed constant throughout.

(28) J. A. Bassham, Thesis, submitted as partial fulfillment of requirements for the degree of Doctor of Philosophy, University of California, 1949.

(29) J. A. Barltrop, P. M. Hayes and M. Calvin, to be published.

(30) I. C. GunsaIus, Symposium on "Mechanism of Enzyme Action," McColiumPratt Institute, Johns Hopkins University, 1953, to be published.

(3I) A. L. Iohninger, "Phosphorus Metabolism, VoI. I," Johns Hopkins University Press (1951), page 344.

(32) Z. Dische and E. Pollaczek, paper presented at Second International Congress of Biochemistry, Paris, France, 1952.

(33) A. C. Neish, paper presented at American Society of Bacteriologists meeting, San Francisco, 1953.

(34) H. B. Wolin, B. L. Horecker, M. Gibbs and H. Klenow, paper presented at meeting of American Institute of Biological Sciences, Nadison, Wisconsin, 1953.

(35) This paper was presented before the Division of Biological Chemistry, Anerican Chemical Society at the 124th National Neeting, Chicago, IIlinios, September, 1953. 